Article

\title{
Long-Term, Simultaneous Impact of Antimicrobials on the Efficiency of Anaerobic Digestion of Sewage Sludge and Changes in the Microbial Community
}

\author{
Małgorzata Czatzkowska ${ }^{1}\left(\mathbb{D}\right.$, Monika Harnisz ${ }^{1, *}$, Ewa Korzeniewska ${ }^{1}$ (D) Izabela Wolak $^{1}$ (D), \\ Paulina Rusanowska ${ }^{2}$ (D) , tukasz Paukszto ${ }^{3}$ (D) Jan P. Jastrzębski ${ }^{3}$ and Sylwia Bajkacz ${ }^{4,5}$
}

1 Department of Water Protection Engineering and Environmental Microbiology, University of Warmia and Mazury in Olsztyn, Prawocheńskiego 1, 10-720 Olsztyn, Poland; malgorzata.czatzkowska@uwm.edu.pl (M.C.); ewa.korzeniewska@uwm.edu.pl (E.K.); izabela.koniuszewska@uwm.edu.pl (I.W.)

2 Department of Environmental Engineering, University of Warmia and Mazury in Olsztyn, Warszawska 117a, 10-720 Olsztyn, Poland; paulina.jaranowska@uwm.edu.pl

3 Department of Plant Physiology, Genetics and Biotechnology, University of Warmia and Mazury in Olsztyn, Oczapowskiego 1A, 10-719 Olsztyn, Poland; pauk24@gmail.com (Ł.P.); jan.jastrzebski@uwm.edu.pl (J.P.J.)

4 Department of Inorganic, Analytical Chemistry and Electrochemistry, Silesian University of Technology, Krzywoustego 6, 44-100 Gliwice, Poland; sylwia.bajkacz@polsl.pl

5 Centre for Biotechnology, Silesian University of Technology, Krzywoustego 8, 44-100 Gliwice, Poland

* Correspondence: monikah@uwm.edu.pl

check for updates

Citation: Czatzkowska, M.; Harnisz, M.; Korzeniewska, E.; Wolak, I.; Rusanowska, P.; Paukszto, Ł.; Jastrzẹbski, J.P.; Bajkacz, S. Long-Term, Simultaneous Impact of Antimicrobials on the Efficiency of Anaerobic Digestion of Sewage Sludge and Changes in the Microbial Community. Energies 2022, 15, 1826. https://doi.org/10.3390/en15051826 Academic Editor: Byong-Hun Jeon

Received: 31 January 2022 Accepted: 26 February 2022 Published: 1 March 2022

Publisher's Note: MDPI stays neutral with regard to jurisdictional claims in published maps and institutional affiliations.

Copyright: (C) 2022 by the authors. Licensee MDPI, Basel, Switzerland. This article is an open access article distributed under the terms and conditions of the Creative Commons Attribution (CC BY) license (https:// creativecommons.org/licenses/by/ $4.0 /$ )

\begin{abstract}
The aim of this study was to evaluate the influence of simultaneous, long-term exposure to increasing concentrations of three classes of antimicrobials ( $\beta$-lactams, fluoroquinolones and nitroimidazoles) on: (1) the efficiency of anaerobic digestion of sewage sludge, (2) qualitative and quantitative changes in microbial consortia that participate in methane fermentation, and (3) fate of antibiotic resistance genes (ARGs). Long-term supplementation of sewage sludge with a combination of metronidazole, amoxicillin and ciprofloxacin applied at different doses did not induce significant changes in process parameters, including the concentrations of volatile fatty acids (VFAs), or the total abundance of ARGs. Exposure to antibiotics significantly decreased methane production and modified microbial composition. The sequencing analysis revealed that the abundance of OTUs characteristic of Archaea was not correlated with the biogas production efficiency. The study also demonstrated that the hydrogen-dependent pathway of methylotrophic methanogenesis could significantly contribute to the stability of anaerobic digestion in the presence of antimicrobials. The greatest changes in microbial biodiversity were noted in substrate samples exposed to the highest dose of the tested antibiotics, relative to control. The widespread use of antimicrobials increases antibiotic concentrations in sewage sludge, which may decrease the efficiency of anaerobic digestion, and contribute to the spread of antibiotic resistance (AR).
\end{abstract}

Keywords: sewage sludge; long-term anaerobic digestion; methane; antimicrobial influence; microbial community; antibiotic resistance

\section{Introduction}

Due to their extensive use in recent years, antibiotics have emerged as a new type of pollutant that poses a threat to the environment and public health [1]. The environment is contaminated with antimicrobials from various sources, including pharmaceutical plants, agriculture, veterinary and human health care facilities. Direct human consumption of drugs is one of the sources of antimicrobials and their metabolites in wastewater [2]. Moreover, inappropriate disposal of unused and expired drugs increases the pool of antimicrobials in wastewater flowing into wastewater treatment plants (WWTPs). Each year, thousands of tons of antimicrobials and their metabolites are expelled and carried 
with sewage to WWTPs $[2,3]$. Processes like wastewater treatment or anaerobic digestion allow antibiotic degradation, but there is notable variability in antibiotic removal rates as well as problems with their biologically active degradation products [4,5].

The technology involving activated sludge is an effective biological wastewater treatment method. This process generates sewage sludge, including excess activated sludge [6]. Antimicrobials are also detected in water because wastewater is being continuously enriched with these substances. Drugs are strongly absorbed by sewage sludge, and considerable research has been done to determine the influence of antimicrobials on both sewage sludge [7-10] and the environment [10-13].

Sewage sludge from WWTPs requires appropriate management. Anaerobic treatment is a technology that is applied mainly to stabilize sewage sludge [6]. In the process of methane fermentation, complex organic matter undergoes decomposition under anaerobic conditions, which results in the production of biogas composed mainly of methane and carbon dioxide. This technology offers an alternative approach to energy generation that consists of four interdependent stages: hydrolysis, acidogenesis, acetogenesis, and methanogenesis $[14,15]$. Methane production involves a variety of microorganisms that determine the efficiency of the process. The efficiency of methane fermentation is influenced primarily by the presence of inhibitory compounds, including antibiotics, in sewage sludge. Antimicrobial substances can destabilize the entire process and decrease methane production. The accumulation of wastewater-borne antimicrobials in sewage sludge can influence the microbial community associated with various stages of methane fermentation. Methane production can be disrupted by the low activity of various microbial groups and variations in the quantitative and qualitative composition of microbiota [5,15-17]. Antimicrobial substances affect microorganisms in various ways, for example by inhibiting the replication of DNA (nitroimidazoles and fluoroquinolones), transcription of RNA, or generation of ATP. These inhibitors can also disturb the cell wall and nucleotide synthesis ( $\beta$-lactams) and nucleotides, and they can compromise cell division and protein translation $[18,19]$. The presence of antimicrobial substances in anaerobic digesters can exert a direct influence on methane production [20]. In many cases, the efficiency of methane fermentation is often compromised by an increase in the concentration of volatile fatty acids (VFAs) which are generated during methanogenesis and which disrupt the equilibrium between microbial groups participating in the process [16]. A sound knowledge of microbial consortia that are involved in anaerobic processes can be useful in preventing and predicting system failures [21,22]. Despite significant progress in digester engineering and design, the participation of bacteria in methane fermentation continues to pose a challenge.

Antimicrobials that are organic inhibitors of methane fermentation also contribute to antibiotic resistance (AR). The widespread use and misuse of drugs leads to the emergence of microorganisms that carry more than one antibiotic resistance gene (ARG). Like antibiotics, ARGs belong to a new category of pollutants that can influence public safety and health [23-25]. The horizontal gene transfer (HGT) mechanism enables microorganisms to exchange ARGs. Wastewater and sewage sludge are characterized by subinhibitory levels of antimicrobial, and WWTPs are regarded as hotspots of HGT processes and ARG transmission between bacteria [26].

The impact of antimicrobials on anaerobic digestion $[27,28]$ and the elimination of ARGs during methane fermentation $[29,30]$ have been explored by many researchers. These problems were also addressed in our previous research [5,31]. Czatzkowska et al. [5] analyzed the effects of the most popular classes of antibiotics on sewage sludge fermentation. The study focused on the effects of individual antibiotics administered at high doses, and it demonstrated that exposure to single, high doses of antimicrobials during anaerobic digestion affected methane production, the structure of microorganisms and ARGs in sewage sludge. Fermentation, including the microbiological aspects of the process, was most exten-sively influenced by amoxicillin, ciprofloxacin and metronidazole. It should be noted that the cited research was the first study to investigate the effect of metronidazole on methane fermentation. 
Metronidazole, one of the studied antibiotics, is used in human and veterinary medicine to treat infections caused by anaerobic and microaerophilic bacteria as well as protozoa. This antimicrobial drug is diffused across microbial cell membranes, and it is reduced by intracellular proteins, which explains the natural resistance of aerobic bacteria [32]. Metronidazole is active only in anaerobic conditions, and it is often used to treat infections caused by Bacteroidetes, which is one of the largest bacterial phyla involved in methane fermentation. The phylum Bacteroidetes includes $\beta$-lactamase-producing anaerobic bacteria that are often resistant to penicillin [33]. $\beta$-Lactams are the most diverse group of antibiotics that are widely applied in medicine. However, microorganisms have developed resistance to $\beta$-lactams, and the number of resistant strains continues to increase. According to estimates, annual $\beta$-lactam sales account for $65 \%$ of the global market of antibiotics, which raises serious concern in view of growing microbial resistance to this group of drugs. Amoxicillin, a $\beta$-lactamase-sensitive penicillin, is widely used in the treatment of upper respiratory tract infections. This broad-spectrum antimicrobial targets both Gram-negative and Gram-positive bacteria [34,35]. Ciprofloxacin is a broad-spectrum fluoroquinolone antimicrobial that is applied in the treatment of bacterial urinary tract infections and pneumonia [36]. Ciprofloxacin is also administered to prevent infections in cancer patients. Recent research has demonstrated growing levels of microbial resistance to this drug $[37,38]$.

The present study was undertaken to evaluate the simultaneous, long-term influence of antimicrobials on sewage sludge fermentation. The experiment involved three classes of antimicrobials ( $\beta$-lactams, fluoroquinolones and nitroimidazoles) that can potentially influence microorganisms participating in the entire anaerobic treatment process. The antimicrobial substances were selected based on our previous findings [5], as having the most significant, individual impact on biogas production and microbiota structure during anaerobic digestion of this substrate. This study is a continuation of our previous original research into metronidazole's effect on anaerobic digestion. Although the effects of several antibiotics on methane fermentation were previously investigated, these studies did not select the drugs classes currently most commonly used in human medicine [4,39]. Due to the continuous increase in the consumption of antibiotics and their release to wastewater and sewage sludge, we believe that the concept of research on the drug's effect on methane fermentation should include the most common antimicrobial substances consumed by humans. To the best of our knowledge, the concurrent impact of several widely used antimicrobials on methane fermentation of sewage sludge-included in the concept of this study—has not been investigated to date.

In view of the above, this study was undertaken to investigate the concurrent effect of selected antimicrobials on: (1) methane fermentation efficiency, (2) quantitative and qualitative changes in microbial consortia that participate in anaerobic digestion, (3) the fate of ARGs and the spread of AR. The study was designed to analyze the simultaneous impact of amoxicillin, ciprofloxacin and metronidazole on the anaerobic digestion of sewage sludge during long-term exposure to the examined antimicrobials. The presence of synergistic and antagonistic interactions between the studied antibiotics was determined. The results will provide new insights into antimicrobials' impact on the efficiency of methane fermentation of sewage sludge and changes in the structure of microbial consortia. Special emphasis was placed on the spread of AR. The results were analyzed with the use of high-throughput sequencing, a modern tool for typing microbial isolates in molecular microbiology.

\section{Materials and Methods}

\subsection{Substrate and Inoculum}

Sewage sludge was collected from the Łyna Municipal Wastewater Treatment Plant (WWTP) located in Olsztyn, Poland. The plant treat wastewater in an amount corresponding to approximately $177,000 \mathrm{PE}$. The average wastewater flow is $30,000 \mathrm{~m}^{3} /$ day. Fermentation chambers are fed with sludges produced during wastewater treatment process (from primary settling tanks and gravity thickeners) and operated at load of $0.055 \mathrm{~m}^{3} \cdot \mathrm{m}^{-3} \cdot \mathrm{d}^{-1}$, 
sludge retention time of 18.5 days, and the temperature of $34-35{ }^{\circ} \mathrm{C}$. Produced biogas is used to generate heat in WWTP buildings.

Sewage sludge had the following characteristics: total solids (TS) - $52.1 \pm 11.4 \mathrm{mg}$ TS/g; volatile solids (VS) - $39.9 \pm 9.6 \mathrm{mg}$ VS/g; $\mathrm{pH}-6.35 \pm 0.3$; total phosphorus (TP) $2.0 \pm 0.5 \mathrm{mg} \mathrm{TP} / \mathrm{g}$; total nitrogen $(\mathrm{TN})-4.3 \pm 1.6 \mathrm{mg} \mathrm{T} / \mathrm{g}$. The substrate was stored at a temperature of $5{ }^{\circ} \mathrm{C}$ before analysis. The inoculum (anaerobic sludge) was obtained from a fermentation tank in the same WWTP. Anaerobic sludge had the following characteristics: $55.7 \pm 1.5 \mathrm{~g}$ TS/L, $42.8 \pm \mathrm{g}$ VS $/ \mathrm{L}, \mathrm{pH}$ of $8.01 \pm 0.4,0.6 \pm 0.2 \mathrm{mg} \mathrm{TP} / \mathrm{g}, 2.1 \pm 0.4 \mathrm{mg} \mathrm{TN} / \mathrm{g}$.

\subsection{Methane Fermen Tation}

Sewage sludge was treated by anaerobic digestion in semi-continuous flow digesters with a volume of $2 \mathrm{~L}$ (working volume of $1.8 \mathrm{~L}$ ). The digesters were placed in the water bath with a temperature of $37^{\circ} \mathrm{C}$ to maintain mesophilic conditions. The digesters were fed substrate containing a mixture of amoxicillin (AMO), ciprofloxacin (CIP) and metronidazole (MET) or sewage sludge only (control). The experiments were carried out in two replicates. The antibiotics were selected based on the results of our previous research [5]. The three antibiotics selected for this study, individually dosed into sewage sludge in anaerobic bioreactors, caused the most significant effect on methane production, as well as changes in the structure of the microbiota involved in the process and the ARGs profile. The present study consisted of six experimental series that differed in the concentrations of the tested antibiotics (Table 1). The initial concentration of each of the three antibiotics in the mixture dosed to sewage sludge during the first experimental series (D1) was similar to the concentration of these drugs in the wastewater flowing into the WWTP from which the sludge was obtained [40]. The concentrations of the antibiotics added to the digester were increased after doubling the hydraulic volume of each digester. Each of the experimental series lasted 45 days on average, and the entire study lasted 268 days.

Table 1. Concentrations of the antibiotics used in the experiment.

\begin{tabular}{cccc}
\hline & \multicolumn{3}{c}{ Antibiotic Concentration $(\mu \mathrm{g} / \mathrm{mL})$} \\
\hline Dose ID & AMO & CIP & MET \\
\hline D1 & 1 & 0.25 & 0.25 \\
\hline D2 & 2 & 0.5 & 0.5 \\
\hline D3 & 4 & 1 & 1 \\
\hline D4 & 8 & 4 & 4 \\
\hline D5 & 16 & 8 & 8 \\
\hline D6 & 36 & 16 & 16 \\
\hline
\end{tabular}

The digesters were operated at an organic loading rate of $2.8 \mathrm{~g} \mathrm{VS} \cdot \mathrm{L}^{-1} \cdot \mathrm{d}^{-1}$. Hydraulic retention time was 22 days. The digesters were equipped with a mechanical stirrer and a feeding and discharge system, and they were connected to an automatic methane potential test system (AMPTS II) (Bioprocess Control, Lund, Sweden) which measured the amount of the produced methane. Biogas quality was analyzed in a gas chromatograph equipped with a thermal conductivity detector (GC-TCD, Agilent Technologies 7890 A, Irving, TX, USA). Gas was normalized for standard temperature (273.2 K) and pressure (1.01325 bar).

\subsection{Sampling}

During each experimental series, representative digestate samples were collected at weekly intervals from digester containing substrate supplemented with antibiotics (process digester) and sewage sludge only (control digester). To monitor the digestion process, digestate samples were analyzed for $\mathrm{pH}$, FOS/TAC ratio (the TAC value denotes the estimated buffer capacity of the sample, and the FOS value denotes the content of volatile acids), and the content of TS, VS, TN and TP. A total of 56 samples, including 28 samples 
from the control bioreactor and 28 samples from the process bioreactor, were collected. The nomenclature adopted for the examined samples is presented in Table 2. All samples collected from process and control bioreactors were analyzed for methane production and VFA content. Samples for DNA isolation and sequencing were collected from the process bioreactors at the beginning, in the middle and at the end of each experimental series, whereas one sample was collected from the control bioreactor during the first, fourth and last experimental series.

Table 2. Nomenclature for the samples used in the analyses of methane production, VFA (volatile fatty acid) content and sequencing analyses, including sample IDs.

\begin{tabular}{|c|c|c|c|c|c|}
\hline & \multirow{4}{*}{$\begin{array}{c}\text { Sample } \\
1\end{array}$} & \multicolumn{2}{|c|}{ Methane and VFA Analyses } & \multicolumn{2}{|c|}{ Sequencing } \\
\hline \multirow{6}{*}{ Experimental series 1} & & Process Bioreactor & Control Bioreactor & Process Bioreactor & Control Bioreactor \\
\hline & & \multicolumn{4}{|c|}{ Sample ID } \\
\hline & & D1.1 & C1.1 & D1.1 & C1.1 \\
\hline & 2 & D1.2 & C1.2 & D1.2 & na \\
\hline & 3 & D1.3 & C1.3 & na & na \\
\hline & 4 & D1.4 & C1.4 & D1.4 & na \\
\hline \multirow{7}{*}{ Experimental series 2} & \multirow{2}{*}{ Sample } & Process bioreactor & Control bioreactor & Process bioreactor & Control bioreactor \\
\hline & & \multicolumn{4}{|c|}{ Sample ID } \\
\hline & 1 & $\mathrm{D} 2.1$ & $\mathrm{C} 2.1$ & $\mathrm{D} 2.1$ & na \\
\hline & 2 & $\mathrm{D} 2.2$ & $\mathrm{C} 2.2$ & na & na \\
\hline & 3 & D2.3 & $\mathrm{C} 2.3$ & D2.3 & na \\
\hline & 4 & D2.4 & $\mathrm{C} 2.4$ & na & na \\
\hline & 5 & D2.5 & $\mathrm{C} 2.5$ & $\mathrm{D} 2.5$ & na \\
\hline \multirow{6}{*}{ Experimental series 3} & \multirow{2}{*}{ Sample } & Process bioreactor & Control bioreactor & Process bioreactor & Control bioreactor \\
\hline & & \multicolumn{4}{|c|}{ Sample ID } \\
\hline & 1 & D3.1 & C3.1 & D3.1 & na \\
\hline & 2 & D3.2 & $\mathrm{C} 3.2$ & na & na \\
\hline & 3 & D3.3 & C3.3 & D3.3 & na \\
\hline & 4 & D3.4 & C3.4 & D3.4 & na \\
\hline \multirow{7}{*}{ Experimental series 4} & \multirow{2}{*}{ Sample } & Process bioreactor & Control bioreactor & Process bioreactor & Control bioreactor \\
\hline & & \multicolumn{4}{|c|}{ Sample ID } \\
\hline & 1 & D4.1 & C4.1 & D4.1 & C4.1 \\
\hline & 2 & $\mathrm{D} 4.2$ & C4.2 & na & na \\
\hline & 3 & D4.3 & C4.3 & na & na \\
\hline & 4 & D4.4 & C4.4 & $\mathrm{D} 4.4$ & na \\
\hline & 5 & D4.5 & C4.5 & D4.5 & na \\
\hline \multirow{7}{*}{ Experimental series 5} & \multirow{2}{*}{ Sample } & Process bioreactor & Control bioreactor & Process bioreactor & Control bioreactor \\
\hline & & \multicolumn{4}{|c|}{ Sample ID } \\
\hline & 1 & D5.1 & C5.1 & D5.1 & na \\
\hline & 2 & D5.2 & C5.2 & na & na \\
\hline & 3 & D5.3 & C5.3 & D5.3 & na \\
\hline & 4 & D5.4 & C5.4 & na & na \\
\hline & 5 & D5.5 & C5.5 & D5.5 & na \\
\hline
\end{tabular}


Table 2. Cont.

\begin{tabular}{|c|c|c|c|c|c|}
\hline & & \multicolumn{2}{|c|}{ Methane and VFA Analyses } & \multicolumn{2}{|c|}{ Sequencing } \\
\hline & \multirow{2}{*}{ Sample } & Process bioreactor & Control bioreactor & Process bioreactor & Control bioreactor \\
\hline & & \multicolumn{4}{|c|}{ Sample ID } \\
\hline & 1 & D6.1 & C6.1 & D6.1 & na \\
\hline \multirow[t]{4}{*}{ Experimental series 6} & 2 & D6.2 & C6.2 & na & na \\
\hline & 3 & D6.3 & C6.3 & D6.3 & na \\
\hline & 4 & D6.4 & C6.4 & na & na \\
\hline & 5 & D6.5 & C6.5 & D6.5 & C6.5 \\
\hline
\end{tabular}

D-dose ID, C-control samples, na-not analyzed. For example, D1.1 is the first sample from the process bioreactor that was supplemented with the first dose, $\mathrm{C} 1.4$ is the fourth sample from the control bioreactor etc.

\subsection{Analytical Procedures}

The content of VFAs was determined based on a previously described method [41] with the use of a gas chromatograph (Brüker 450-GC, Billerica, MA, USA) with a flame ionization detector (FID) and a CP-FFAP CB capillary column $(25 \mathrm{~m} \times 0.53 \mathrm{~mm})$. The FOS/TAC ratio was determined with the TitraLab AT1000 Series Titrator (Hach, Ames, IA, USA). The content of TS and vs. in biomass samples was determined in a gravimetric analysis [42]. The content of TN and TP in the samples was determined using the DR 5000 spectrophotometer with the HT $200 \mathrm{~s}$ mineralizer (Hach, Ames, IA, USA). All measurements were performed in duplicate.

\subsection{Isolation of Genomic DNAs}

One $\mathrm{mL}$ of each sample was transferred to sterile $2 \mathrm{~mL}$ Eppendorf tubes (Eppendorf, Germany) and centrifuged (5415R Centrifuge, Eppendorf, Germany) for 15 min at $9000 \mathrm{rpm}$ at a temperature of $4{ }^{\circ} \mathrm{C}$. The obtained supernatant was discarded. The procedure was repeated. The FastDNA ${ }^{\mathrm{TM}}$ Spin Kit for Soil (MP Biomedicals, Irvine, CA, USA) was used for DNA isolation from the acquired pellet, according to the instructions supplied by the manufacturer. The quantity and quality of the obtained genetic material were measured using a spectrophotometer (Multiskan Sky, Thermo Scientific, Waltham, MA, USA). DNA was isolated in a total amount of $150 \mu \mathrm{L}$ from two replicates and was stored until further analysis at $-20^{\circ} \mathrm{C}$.

\subsection{Library Preparation and Sequencing}

Metagenomic sequencing was performed by Macrogen (Seoul, Korea) with the TruSeq DNAPCR-Free Kit (Illumina Inc., San Diego, CA, USA). Index sequences were attached to each sample during the preparation of the library. Barcoded libraries were sequenced by using a $2 \times 151 \mathrm{bp}$ paired-end protocol in the Illumina NovaSeq 64,000 system (Illumina Inc, San Diego, CA, USA). A total of 21 metagenomic samples were placed under accession No. PRJEB48473 in the European Nucleotide Archive (ENA) database.

\subsection{Bioinformatics Analysis}

Before downstream analysis, the quality of raw reads was estimated using Kneaddata v. 0.7.6 software (Huttenhower Lab, Harvard Chan Center for the Microbiome in Public Health, Boston, MA, USA) [43]. The raw data were trimmed by eliminating reads with a low PHRED score $(<20)$ and removing reads with nonbacterial contamination. The human genome (hg37; GenBank ID_-GCF_000001405.13) was used as contamination reference sequences for quality control. Ribosomal RNA reads were also recognized and eliminated with Kneaddata software. Filtered reads were used as the inputs for downstream analyses. Humann2 v.0.11.2 software (Huttenhower Lab) [44] and UniRef90 database were used to explore the gene family abundance. The bacterial community size was determined by 
Metaphlan v. 2.0 (Huttenhower Lab) [45]. Kneaddata, Metaphlan, and Humann2 were used as part of the Biobakery v.0.15.1 workflow.

\subsection{Statistical Analysis}

The influence of antibiotics on methane and VFA production was analyzed by twoway ANOVA, and the results were presented in line graphs (GraphPad Software Inc., San Diego, CA, USA).

The structure of microbial consortia was visualized by phyloseq (San Francisco, CA, USA) [46], circlize 0.4.13 (Heidelberg, Germany) [47] R packages and graphlan 1.1.3 (Huttenhower Lab) [48] software. Trimmed sequences were used to analyze ARG abundance and diversity in the ARG-OAP v.2.0 pipeline (University of Hong Kong, Hong Kong, China) [49]. Antibiotic resistance genes were annotated, and gene type, subtype, and abundance were determined for each gene. Heatmaps showing microbial community structure and ARG abundance were constructed using hclust2 python script (Segata Lab, University of Trento, Trento, Italy) [50]. Pearson's correlation coefficients were calculated with the custom $\mathrm{R}$ function in github [51] to determine the strength of the relationships between the abundance of ARGs and the microbial communities.

Diagrams were generated and the remaining calculations were ran in Microsoft Excel 2013 (Redmond, WA, USA) and GraphPad Software Inc. The abundance of selected microbial groups in samples from process digesters was compared by Spearman's rankorder correlation analysis and Kruskal-Wallis non-parametric test for several independent samples (Statistica 13.1, Statsoft, Krakow, Poland). The relationships between microbial biodiversity in bioreactors, the abundance of ARGs and methane production were examined by principal component analysis (PCA, Statistica 13.1).

\section{Results and Discussion}

\subsection{The Impact of Increasing Antibiotic Concentrations on the Efficiency of Anaerobic Digestion}

The key stages of anaerobic digestion involve hydrolysis, acidogenesis, acetogenesis and methanogenesis. The products of each stage act as substrates for successive stages, and methane and VFA concentrations indicate which stage was inhibited or compromised. To determine the influence of antibiotics on the methane fermentation of sewage sludge, the production of methane and VFAs was monitored in the control bioreactor and in the process bioreactor where sewage sludge was exposed to a mixture of metronidazole, amoxicillin and ciprofloxacin applied at increasing concentrations over a long period of time. The results of the standard technological analyzes $(\mathrm{pH}, \mathrm{FOS} / \mathrm{TAC}, \mathrm{TS}, \mathrm{VS}, \mathrm{TP}$ and $\mathrm{TN})$ are included in Table S1.

Similar trends in methane production were observed in the control bioreactor and in the process bioreactor where sewage sludge was exposed to a combination of the tested antibiotics (Figure 1). However, the efficiency of methane production was lower in the process bioreactor than in the control bioreactor, and the observed differences were significant $(p<0.05)$ (Table S2). An analysis of average methane production in each experimental series demonstrated the greatest decrease in methane production efficiency in the bioreactor supplemented with the first (D1) and the second (D2) dose (by 8.5 and $11.1 \mathrm{NL} \cdot \mathrm{kgVS}^{-1}$, respectively), relative to control. Average methane production in the process bioreactor decreased with a rise in antibiotic concentrations (D3-D6) in the supplemented substrate relative to control. These findings suggest that prolonged exposure to a combination of antimicrobials influenced microbial acclimation inside the bioreactor, and similar observations were made by other authors [52,53]. Acclimation promotes microbial adaptation and selective growth of microbial groups that play a key role in methane fermentation [54]. 


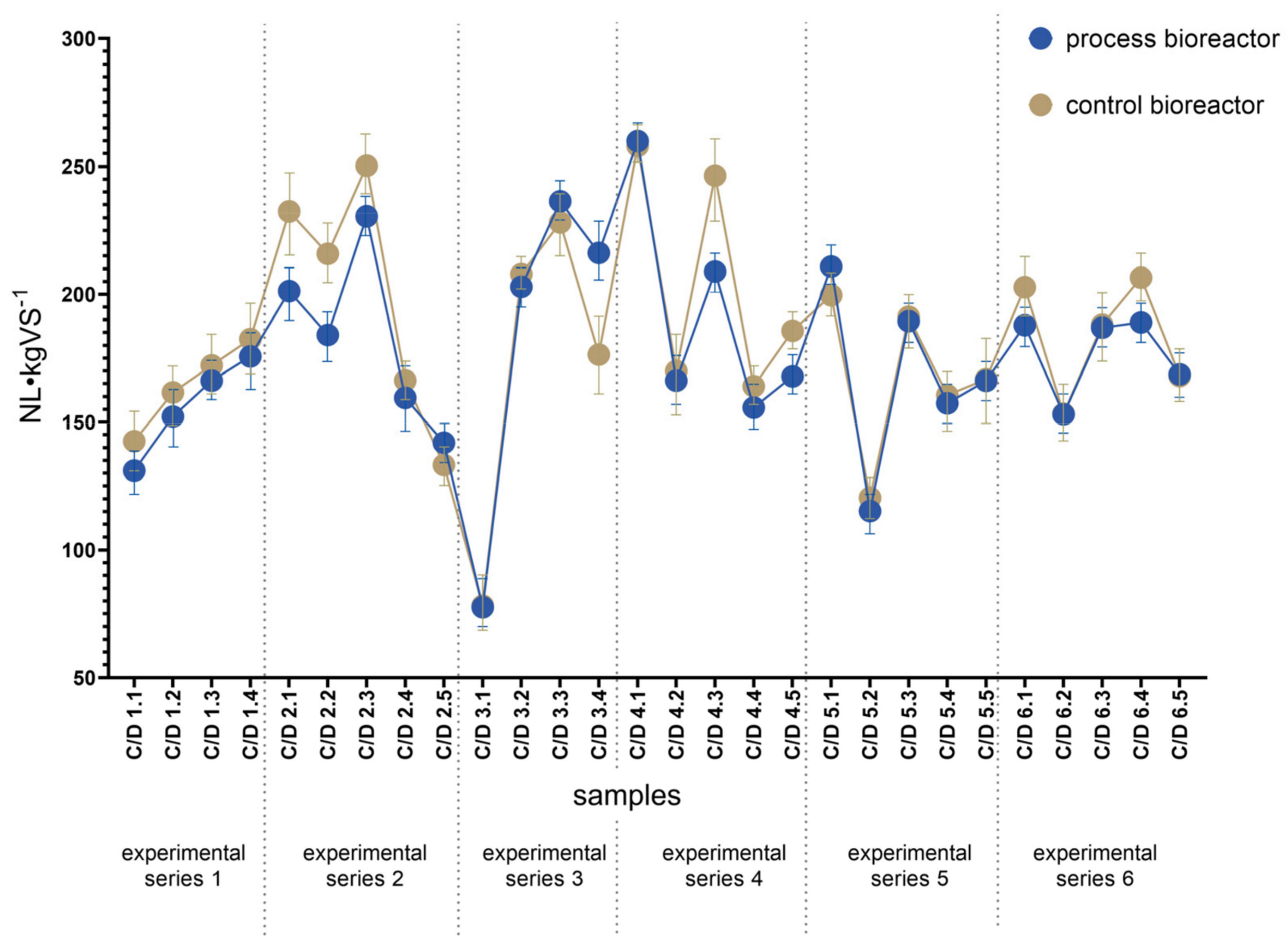

Figure 1. Methane production $\left(\mathrm{NL} \cdot \mathrm{kgVS}^{-1}\right)$ in the process and control bioreactors. C-control samples, D-dose ID. For example, "C/D 1.1" indicates samples C1.1 and D1.1 (green and blue points on the line graph, respectively).

In our previous study [5], high individual doses of metronidazole (512 $\mu \mathrm{g} / \mathrm{g})$, amoxicillin $(1024 \mu \mathrm{g} / \mathrm{g})$ and ciprofloxacin $(512 \mu \mathrm{g} / \mathrm{g})$ significantly decreased the efficiency of methane production (by $228.5,74.7$ and $108.4 \mathrm{NL} \cdot \mathrm{kgVS}^{-1}$, respectively) during the anaerobic digestion of sewage sludge relative to control. In the present study, sewage sludge was exposed to a combination of three antimicrobials applied at low concentrations, and the resulting decrease in biogas production was less pronounced than in our previous research. The observed differences in methane production can be probably attributed to different antibiotic concentrations. Moreover, synergistic interactions between metronidazole, amoxicillin and ciprofloxacin can be ruled out within the range of concentrations tested in this study. According to the literature [55,56], low concentrations of selected antimicrobials do not always disrupt anerobic digestion, and methane production decreases only when a certain threshold concentration of the drug is achieved. Other authors reported that in environments characterized by low antibiotic concentrations, such as municipal wastewater and sewage sludge, antimicrobials exert a minimal impact on the overall efficiency of methane production [54,57].

Changes in the content of VFAs, the main products of protein and carbohydrate hydrolysis during anaerobic digestion, are an important determinant of the efficiency of methane fermentation [58]. The accumulation of VFAs in anaerobic bioreactors points to the inhibition of acetogenesis or methanogenesis. In the present study, no significant differences in the concentrations of individual VFAs $(p>0.05)$ were found between sewage sludge samples collected from process and control bioreactors (Table S3). However, a 
sudden increase in the concentrations of butyric acid (D1, D2) and isovaleric acid (D3) was noted in samples from the process bioreactor (Figure S1). The observed differences did not exceed 1-2 g/L and were not statistically significant, but they could have resulted from a decrease in the efficiency of acetogenesis. Acetogenic bacteria convert butyric and isovaleric acids to acetic acid which is utilized by acetoclastic methanogens in methane production. It should be noted that acetogenesis plays an important role in biogas production, and around $70 \%$ of methane is produced during acetate reduction [59]. Acetate concentration decreased rapidly after the substrate was supplemented with antimicrobial doses D1-D3 (Figure S1). As previously mentioned, the greatest decrease in methane production relative to control was also observed after the application of the lowest drug doses (Figure 1). The influence of the tested combination of antibiotics on microbial consortia, including methanogens, is discussed in detail in Section 3.2.

\subsection{Diversity of Microbial Consortia}

The sequencing analysis supported the identification of nine dominant bacterial phyla in sewage sludge subjected to anaerobic digestion: Firmicutes, Nitrospirae, Chloroflexi, Tenericutes, Acidobacteria, Bacteroidetes, Actinobacteria, Proteobacteria and Candidatus Cloacimonetes (Figure 2).

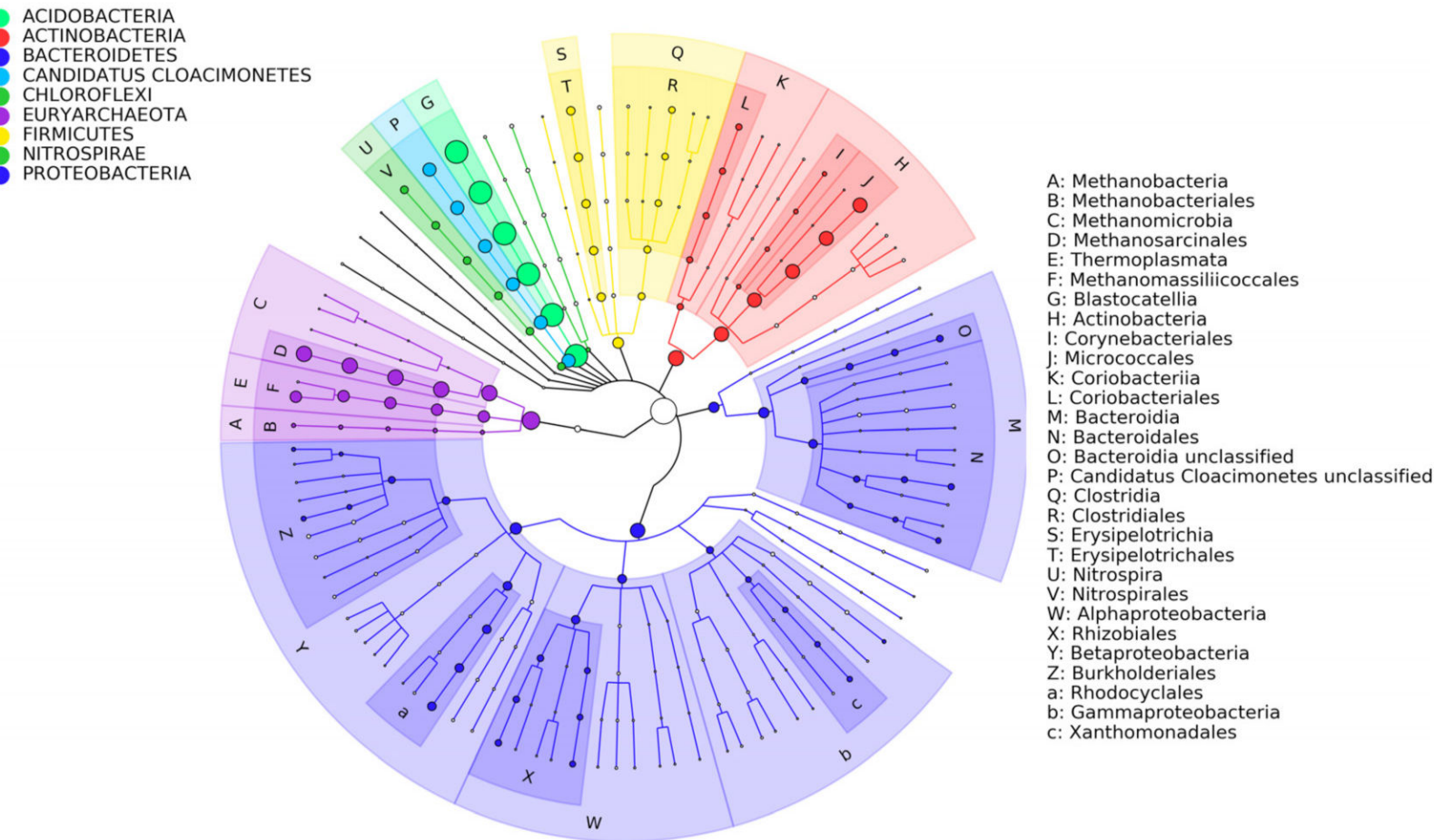

Figure 2. The structure of all microbial consortia in the sequenced samples of sewage sludge. Phylum nodes are colored, and branch areas are shaded. The first two outer tracks (with letters) indicate Classes and Orders. The next seven tracks (Species, Genera, Family, Order, Class, Phylum, Kingdom) describe relative bacterial community abundance calculated by Metaphlan software. The size of the node is relative to the abundance of each taxonomic level.

Bacteria of the phylum Acidobacteria were predominant in sewage sludge samples collected from both the control and process bioreactors, and the abundance of Acidobacteria differed significantly between substrates exposed to antibiotics and the control substrate. Acidobacteria are ubiquitous in soil ecosystems, and they are capable of decomposing various carbon sources, from simple sugars to complex substrates [60]. Acidobacteria are also highly prevalent in WWTPs [61]. The number of OTUs characteristic of Acidobacteria decreased gradually in the control and process bioreactors in the first three experimental series. A 
comparison of the corresponding OTU values revealed a decrease of $10 \mathrm{ppm}$ (parts per million) (D4.1 vs. D1.1) in process reactor and a decrease of $20 \mathrm{ppm}$ (C4.1 vs. C1.1) in the control bioreactor (Figure 3A,B, Table S4).
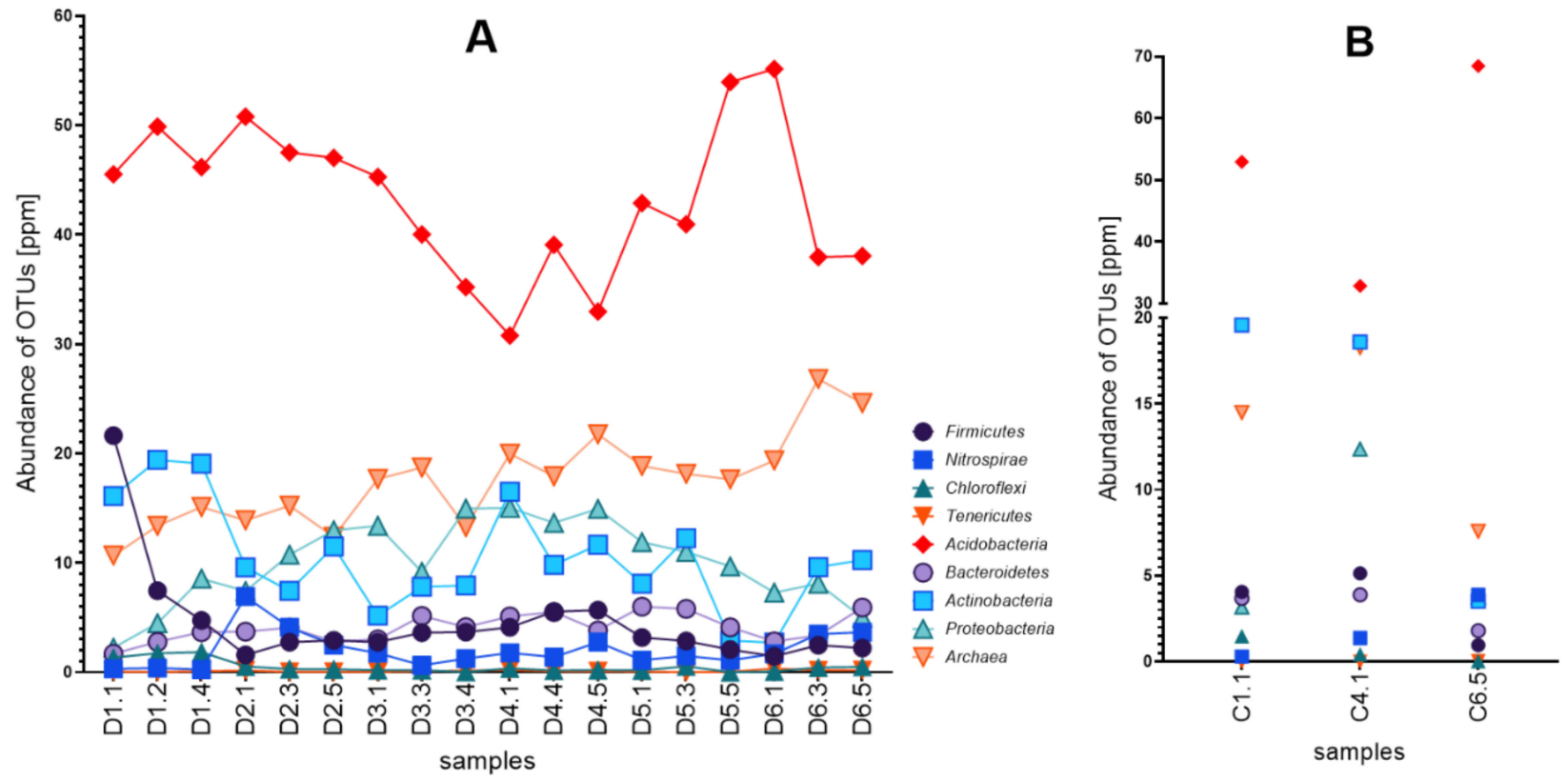

Figure 3. Abundance of OTUs [ppm] characteristic of the dominant microbial phyla in the process (A) and control bioreactors (B). D-dose ID, C-control samples.

During the fourth experimental series, the number of OTUs characteristic of Acidobacteria increased in samples collected from both process and control bioreactors. At the end of long-term anaerobic digestion, the abundance of Acidobacteria differed significantly in digestate samples from process and the control bioreactors and was almost twice higher in the control (38 and $68 \mathrm{ppm}$, respectively). The first five antibiotic doses (D1-D5) did not induce significant changes in the proportions of Acidobacteria during prolonged anaerobic digestion, whereas the last and highest dose (D6) significantly reduced the number of OTUs characteristic of Acidobacteria. These observations suggest that combined exposure to amoxicillin $(36 \mu \mathrm{g} / \mathrm{mL})$, ciprofloxacin $(16 \mu \mathrm{g} / \mathrm{mL})$ and metronidazole $(16 \mu \mathrm{g} / \mathrm{mL}) \mathrm{sig}$ nificantly inhibited the growth of Acidobacteria. It should be noted that Acidobacteria were not identified as the predominant bacterial phylum in other studies analyzing microbial communities in sewage sludge subjected to methane fermentation [62-64]. This is the first study to demonstrate that Acidobacteria, including bacteria of the class Blastocatellia that are ubiquitous in activated sludge flocs [61], are predominant in sewage sludge during anaerobic digestion. These results suggest that sewage sludge from the process bioreactor contained surplus activated sludge from aeration chambers.

Bacterial phyla Firmicutes and Actinobacteria were also ubiquitous at the beginning of anaerobic digestion (D1/C1), and their abundance was determined at 21 and $16 \mathrm{ppm}$ in sewage sludge samples from the process bioreactor and at 4 and $19 \mathrm{ppm}$ in the control bioreactor, respectively. The high initial abundance of Firmicutes in the process bioreactor decreased under exposure to the tested antibiotics. The number of OTUs characteristic of Firmicutes decreased three-fold after the application of the second antibiotic dose (D2), and it decreased ten-fold at the end of the process (D6) relative to initial values (Figure 3A). A similar, but less pronounced trend was observed in control samples. In digestate samples collected at the end of the process (C6.5), the abundance of Firmicutes decreased four-fold relative to initial values (C1.1) (Figure 4B). The phylum Firmicutes was represented mainly by the orders Erysipelotrichales and Clostridiales which contain numerous bacterial species with hydrolytic capabilities [65]. 

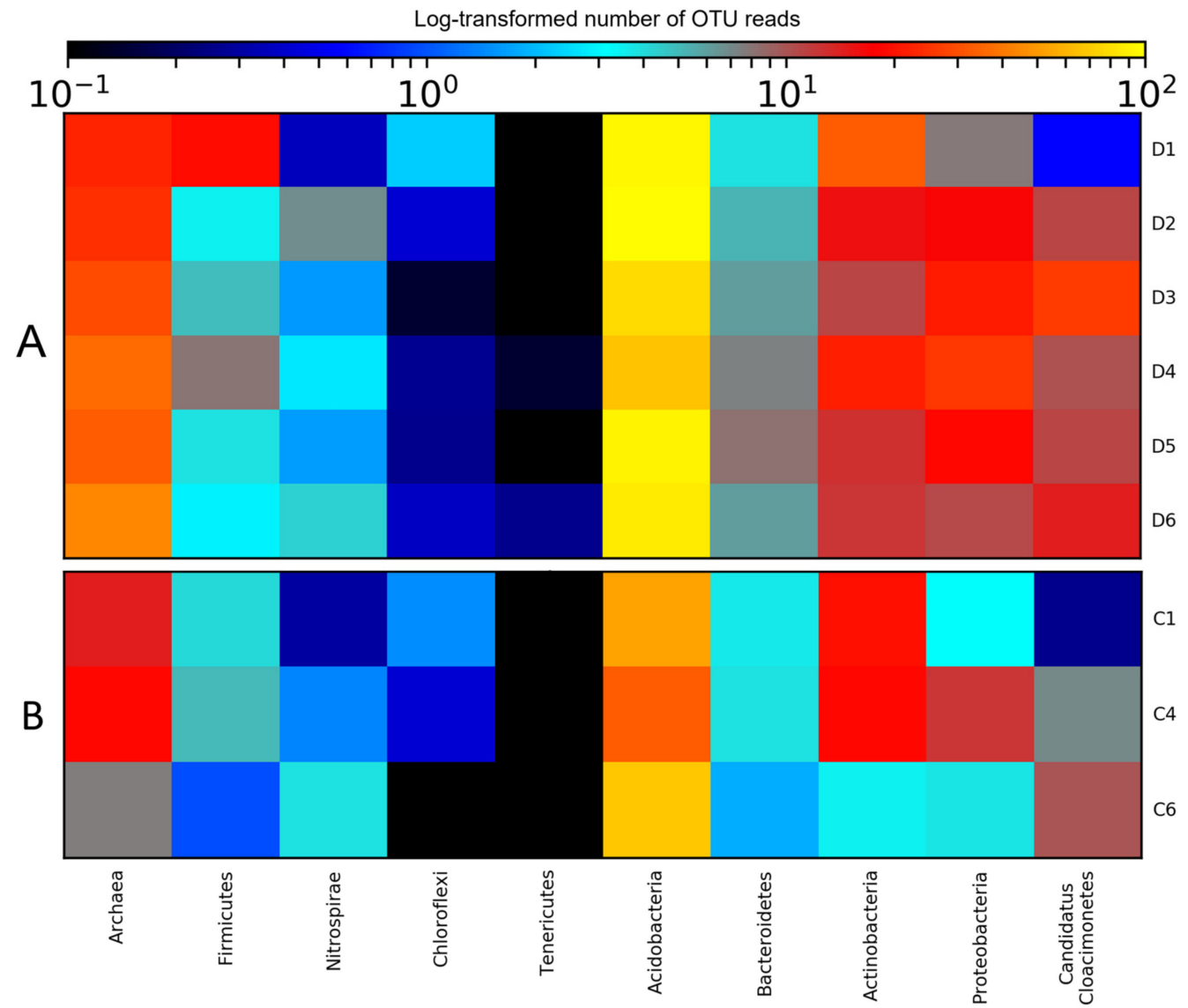

Figure 4. Heatmap with log-transformed number of OTU reads [ppm] at phylum level, presenting changes in microbial abundance in sewage sludge samples from process (A) and control bioreactors (B). The mean values noted in each experimental series used in the analysis. D-dose ID, Ccontrol samples.

A comparison of sewage sludge samples collected from the process bioreactor at the beginning and end of long-term anaerobic digestion revealed that the initially predominant Firmicutes were gradually replaced by bacteria of the unclassified phylum Candidatus Cloacimonetes and phyla Bacteroidetes (order Bacteroidales) and Proteobacteria (orders Burkholderiales, Rhizobiales, Nitrosomonadales and Myxococcales) (Figure 4A). The phyla Firmicutes, Bacteroidetes and Proteobacteria are characteristic of biomass in anaerobic digesters, and they contain many species of acidogenic bacteria [66]. Although Candidatus Cloacimonetes is a novel phylum, several papers indicated the importance of its presence in anaerobic digesters. This phylum has been implicated in extracellular hydrolysis and syntrophic propionate-oxidation [67-71]. As reported by Poirier et al. [70], the prevalence of Cloacimonetes is positively correlated with methane production efficiency. An analysis of the abundance of this phylum in sewage sludge samples at the beginning and at the end of longterm anaerobic digestion revealed an increase in the frequency of readings (from 0.42 to 9.6 and from 0.26 to 9.9 in the process and control bioreactors, respectively) (Figure 3A,B). During the entire process, the prevalence of Candidatus Cloacimonetes and Proteobacteria were similar in substrates sampled from process and control bioreactors, whereas the abundance of OTUs characteristic of Bacteroidetes differed significantly between samples collected from process and control bioreactors. At the end of anaerobic digestion, the abundance of Bacteroidetes was three times lower in samples of control digestate (C6.5) than in samples of experimental digestate (D6.5), whereas the number of OTUs characteristic of Nitrospirae increased (Figure 4B). According to Veloo et al. [72], bacteria of the order Bacteroidales harbor genetic determinants of resistance to $\beta$-lactam antibiotics. In our previous study [5], the abundance of Bacteroidetes OTUs in sewage sludge decreased in response to high concentra- 
tions of metronidazole and ciprofloxacin, but increased under exposure to amoxicillin. In the present study, metronidazole and ciprofloxacin concentrations were two and four times lower, respectively, than amoxicillin concentrations, which could explain the observed increase in the proportion of Bacteroidales in sewage sludge from the process bioreactor.

The abundance of Actinobacteria was similar at the beginning of anerobic digestion in supplemented (D1.1) and control (C1.1) digestate, but it at the end of the process, the prevalence of Actinobacteria decreased significantly-more than five-fold in control samples (C6.5), but only 1.5-fold in supplemented samples. In sewage sludge, Actinobacteria were represented mainly by members of the order Bifidobacteriales, which are characteristic of gut microbiota and constitute a potential reservoir of ARGs [73,74], as well as members of the order Corynebacteriales which are less susceptible to antimicrobials due to the lower permeability of their cell walls $[75,76]$. The abundance of Actinobacteria was higher in digestate samples from the process bioreactor than in control samples, which could be probably attributed to selective pressure exerted by a mixture of the tested antibiotics as well as the lower susceptibility of Actinobacteria to these antimicrobials.

Methanogenic bacteria of the phylum Euryarchaeota are responsible for methanogenesis, the last stage of anaerobic digestion. These bacteria can be divided into three groups based on their methanogenesis pathways and the substrates utilized in methane production: (I) acetoclastic methanogens that use acetate to produce methane; (II) hydrogenotrophic methanogens that utilize formate and hydrogen, and (III) methylotrophic methanogens that rely on methylated compounds such as methanol, methyl sulfides and methylamines as substrates for methane production [66]. In the group of methanogenic archaea, only bacteria of the order Methanosarcinales are capable of metabolizing all three substrates. Methanosarcinales are also the only acetoclastic methanogens to have been identified to date. The group of methylotrophic methanogens includes Methanosarcinales (hydrogen-independent), Methanomassiliicoccales, and one species of the order Methanobacteriales (hydrogen-dependent) [77-79].

The sequencing analysis of sewage sludge samples from process and control bioreactors supported the identification of four orders of methanogens: Methanosarcinales and Methanomicrobiales of the class Methanomicrobia, Methanomassiliicoccales of the class Thermoplasmata, and Methanobacteriales of the class Methanobacteria. The abundance of OTUs characteristic of methanogens was similar in process and control bioreactors at the beginning of anaerobic digestion. Bacteria of the order Methanosarcinales were predominant in the first experimental series (D1/C1) in samples of supplemented (10 ppm) and control digestate (14 ppm) (Figure 5A,B, Table S5). In other studies, acetoclastic methanogens were also predominant in anaerobic digesters, or acetoclastic methanogenesis was the main pathway during the methane production process [80,81]. The number of OTUs characteristic of the orders Methanobacteriales and Methanomicrobiales was low in all analyzed samples. These bacterial orders are associated with the hydrogenotrophic pathway of methane production [82], which suggests that this methanogenic pathway was not predominant in the experiment. Significant differences $(p<0.05)$ in the abundance of Methanosarcinales and Methanomassiliicoccales were noted in samples of process and control digestate over time. In control samples, the proportion of Methanosarcinales decreased significantly from 14 ppm at C1 to $<2$ ppm at C6 (Figure 5B), whereas the abundance of OTUs characteristic of Methanomassiliicoccales increased from $<1 \mathrm{ppm}$ at $\mathrm{C} 1$ to $>5 \mathrm{ppm}$ at C6. However, the total abundance of Archaea in control digestate was relatively low ( $<10 \mathrm{ppm})$, and prolonged anaerobic digestion led to a significant decrease in the number of OTUs characteristic of this microbial kingdom (Figures 3B and 4B). 
A

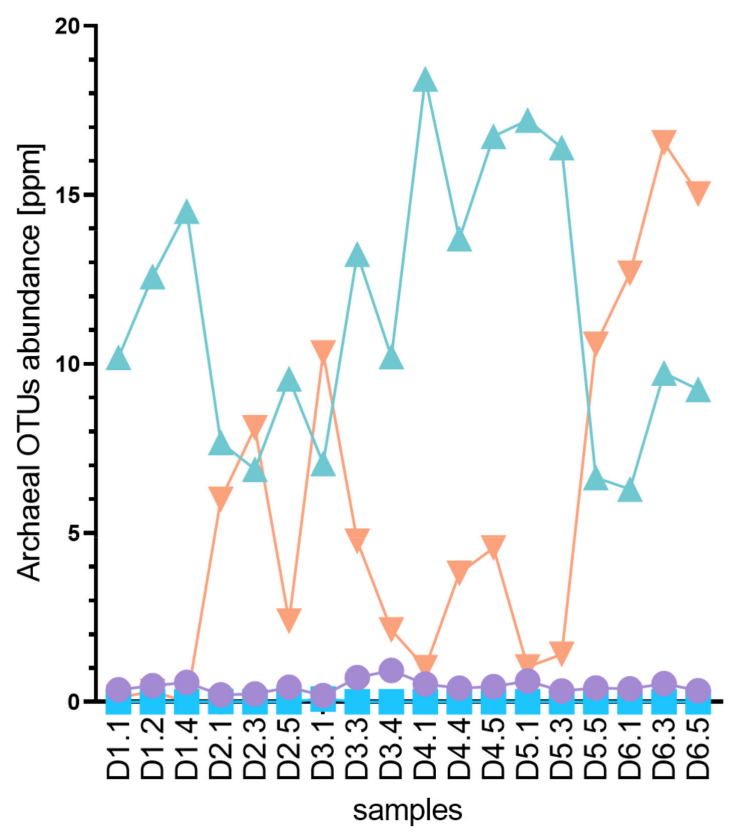

B

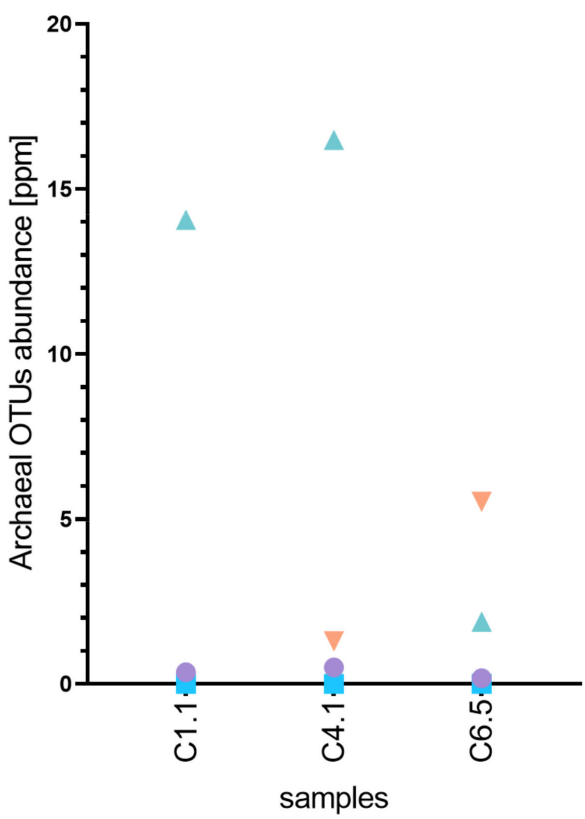

Figure 5. Abundance of OTUs [ppm] characteristic of different orders of the kingdom Archaea in the process (A) and control bioreactors (B). D-dose ID, C-control samples.

The analysis of genome sequences in samples collected from the process bioreactor revealed that the second antibiotic decreased the abundance of Methanosarcinales by $50 \%$ and significantly increased the proportion of Methanomassiliicoccales (from $<1 \mathrm{ppm}$ at D1 to $8 \mathrm{ppm}$ at D2) (Figure 5A). The third antibiotic dose (D3) increased the abundance of Methanosarcinales, but significantly decreased the prevalence of Methanomassiliicoccales. The fifth antibiotic dose (D5) significantly decreased the abundance of OTUs characteristic of Methanosarcinales and increased the proportion of Methanomassiliicoccales, and this trend was maintained until the end of anaerobic digestion. The abundance of Methanosarcinales and Methanomassiliicoccales was bound by a significant negative correlation $(\mathrm{R} 2=-0.68$; $p<0.05$ ) (Table S6). Other researchers have observed that dynamic changes in microbial communities and microbial adaptation to changing environmental conditions are essential for the stable operation of anaerobic digesters $[64,83]$.

At the end of the anaerobic digestion process, the abundance of Methanosarcinales (9 ppm) and Methanomassiliicoccales (15 ppm) was considerably higher in digestate samples collected from the process bioreactor than from the control bioreactor $(<2$ and $>5 \mathrm{ppm}$, respectively). The total abundance of Archaea was significantly higher in the last sample (D6.5) of sewage sludge supplemented with antibiotics (>24 ppm) in comparison with the first sample (D1.1). Moreover, the abundance of Archaea was nearly 2.5 times higher in process digestates than in control digestates $(<10 \mathrm{ppm})$ sampled at the end of the anaerobic digestion process (Figure 3A,B). These results indicate that the prevalence of Archaea in the process digester increased steadily in response to growing concentrations of the tested antibiotics (Figure 4A). Therefore, antibiotic exposure increased the proportion of Archaea in the process bioreactor relative to control, whereas methane production efficiency decreased significantly during the anaerobic digestion process.

An analysis of the prevalence of the predominant methanogens in sewage sludge supplemented with antibiotics revealed that various methanogenic pathways predominated during the anaerobic digestion process. Every decrease in the proportion of Methanosarcinales was accompanied by an increase in the prevalence of Methanomassiliicoccales. According to the literature [81,84], the presence of specific methanogenic inhibitors can increase the activity of other Archaea that utilize different substrates to produce methane. There- 
fore, it can be assumed that hydrogenotrophic, acetoclastic or methylotrophic (hydrogenindependent) pathways were the dominant methanogenic pathways when the structure of archaeal communities was dominated by Methanosarcinales. In turn, in periods characterized by the highest abundance of Methanomassiliicoccales, methane was produced mainly via the hydrogen-dependent methylotrophic pathway. Zhang et al. [85] reported on the high activity of the order Methanomassiliicoccales and its significant role in efficient methane generation. It should also be noted that Methanomassiliicoccales clearly dominated over Methanosarcinales under exposure to the highest antibiotic doses (D5 and D6), and this trend was maintained until the end of the anaerobic digestion process. Moreover, a comparison of Methanomassiliicoccales abundance in the last samples of experimental and control digestates (D6.5 and C6.5) demonstrated that this bacterial order was three times more prevalent in supplemented digestate. The analysis of changes in the structure of microbial communities indicates that the hydrogen-dependent methylotrophic pathway could significantly contribute to the stability of methane generation in the presence of antimicrobial substances.

The anaerobic digestion process is characterized by dynamic changes in the populations of various microbial groups that are directly or indirectly involved in methane production [66]. The sequencing analysis revealed significant differences in the structure of microbiota between samples of control and supplemented sewage sludge during the experiment. Antibiotic exposure induced changes in the structure of microbial populations; therefore, the correlations between dominant bacterial phyla in supplemented samples were analyzed statistically. A correlation analysis was not performed in the control digestate because only a small number of control samples were subjected to sequencing analysis. In sewage sludge exposed to antibiotics, significant positive correlations were observed between the abundance of Archaea and the prevalence of hydrolytic Bacteroidetes and acetogenic Tenericutes (Figure 6, Table S7). The proportions of Bacteroidetes and Tenericutes increased steadily in successive experimental series of anaerobic digestion. The abundance of Acidobacteria decreased in response to higher antibiotic doses, and it was negatively correlated with Archaea and with Bacteroidetes and Proteobacteria whose prevalence increased over time. A significant negative correlation was observed between the abundance of Candidatus Cloacimonetes, which increased steadily during the first three experimental series of anaerobic digestion, and the abundance of Actinobacteria, Firmicutes and Chloroflexi, which decreased over this time. Moreover, a significant positive correlation was noted between Actinobacteria and Firmicutes whose prevalence decreased steadily under exposure to antibiotics.

\subsection{The Prevalence of Antibiotic Resistance Genes in Anaerobic Digesters}

The influence of anaerobic digestion on ARG profiles was examined by several authors [26,27]. A number of studies also evaluated the impact of antimicrobials on the spread of ARGs in bioreactors [86,87]. The observed variations in the profile and abundance of ARGs under exposure to antibiotics can be attributed to changes in the structure of microbial communities inside the bioreactor as well as HGT processes. It should be noted that both intracellular and extracellular ARGs can participate in HGT. Zou et al. (2020) [88] reported a decrease in the abundance of some ARGs during the methane fermentation of sewage sludge. In turn, other authors $[86,87]$ concluded that the diversity and abundance of ARGs are enhanced in the presence of selected antibiotics during anaerobic fermentation. Our previous study demonstrated that high individual doses of metronidazole, amoxicillin and ciprofloxacin significantly modified the overall ARG profile during the methane fermentation of sewage sludge [5].

The sequencing analysis supported the identification of ten classes of ARGs encoding resistance to aminoglycosides, bacitracin, $\beta$-lactams, macrolide-lincosamide-streptogramin (MLS) antibiotics, polymyxins, rifamycins, sulfonamides, tetracyclines and vancomycin, as well as genes encoding multidrug efflux pumps. Sewage sludge samples collected from both process and control bioreactors (Figure 7A,B, Table S8) were characterized by a pre- 
dominance of genes conferring resistance to multiple drugs and MLS antibiotics ( $>20 \mathrm{ppm}$ ). Tetracycline and bacitracin resistance genes were also abundant (5-15 ppm). The antibiotics tested in this study, which were selected based on our previous research [5], belonged to the classes of $\beta$-lactams, fluoroquinolones and nitroimidazoles. However, fluoroquinolone and nitroimidazole resistance genes were not highly prevalent in samples of process and control digestate. Moreover, the abundance of genes encoding resistance to $\beta$-lactams, including amoxicillin, was very low (Figure $8 \mathrm{~A}, \mathrm{~B}$ ). Selective pressure exerted by antibiotics did not specifically target genes encoding resistance to various classes of antimicrobials.

The analysis of changes in the abundance of different ARGs in process and control digestate revealed significant changes in the ARG profile during long-term anaerobic digestion. However, a comparison of the first and last samples of experimental and control digestates (D1.1 vs. C1.1 and D6.5 vs. C6.5, respectively) demonstrated that exposure to the tested combination of antibiotics applied at relatively low and increasing concentrations did not induce significant changes in the abundance of specific ARG groups. Total ARG abundance decreased in both process and control (Table S8) digestates at the end of fermentation. In both bioreactors, average ARG abundance was similar at the beginning and end of anaerobic digestion (91 ppm at D1 and C1; 86 and 87 ppm at D6 and $\mathrm{C} 6$, respectively) (Figure 8A,B, Table S8). However, it should be noted that the prevalence of multidrug resistance genes increased in samples of supplemented sewage sludge, whereas a reverse trend was observed in control samples (Table S8) during long-term methane fermentation. The transfer of multidrug resistance genes between bacteria poses a serious public health threat around the world [89].

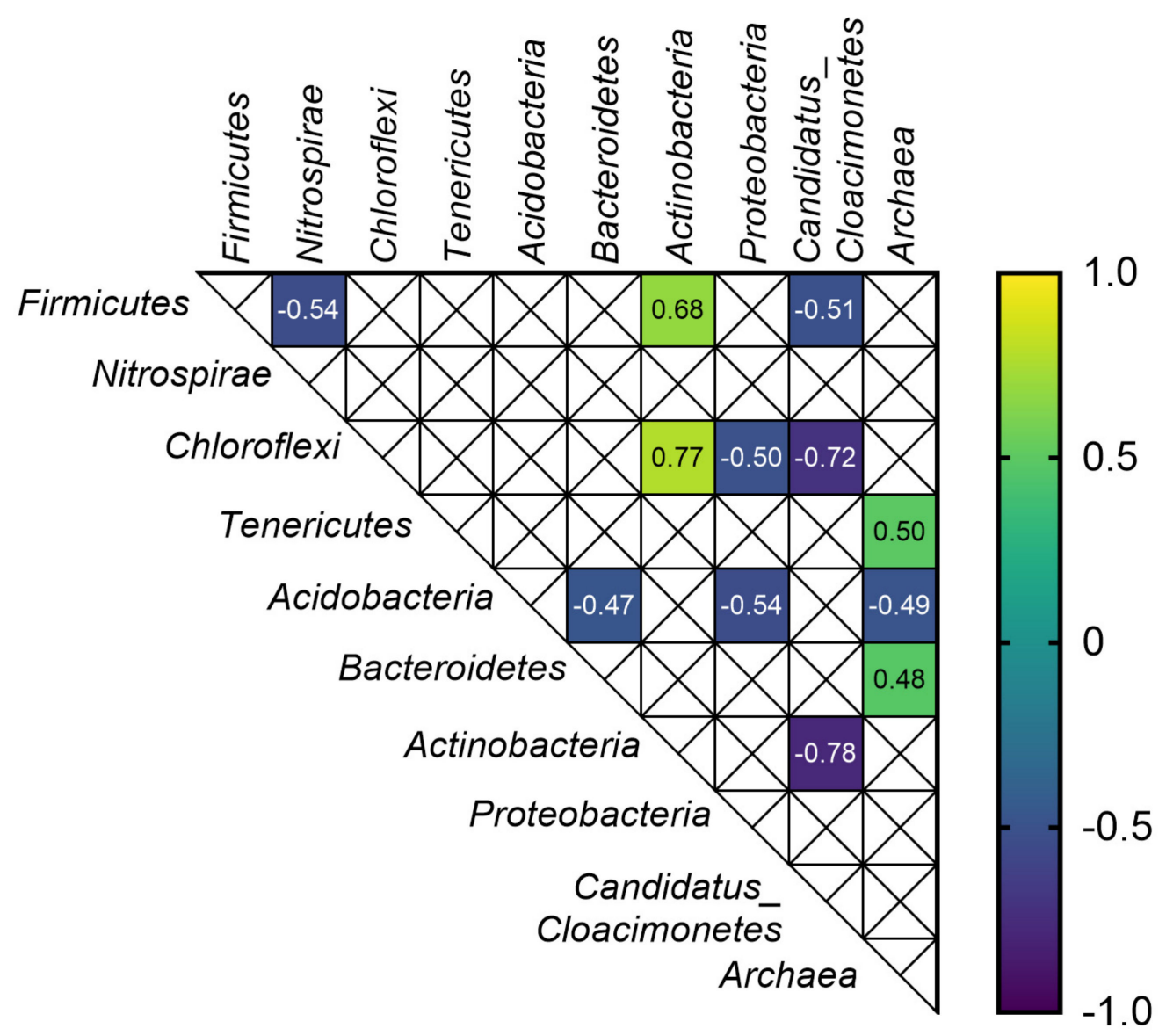

Figure 6. Significant correlations between dominant microorganisms in the process bioreactor. Positive correlations are marked in green, and negative correlations are marked in blue. Color intensity is proportional to the correlation coefficients. 
A

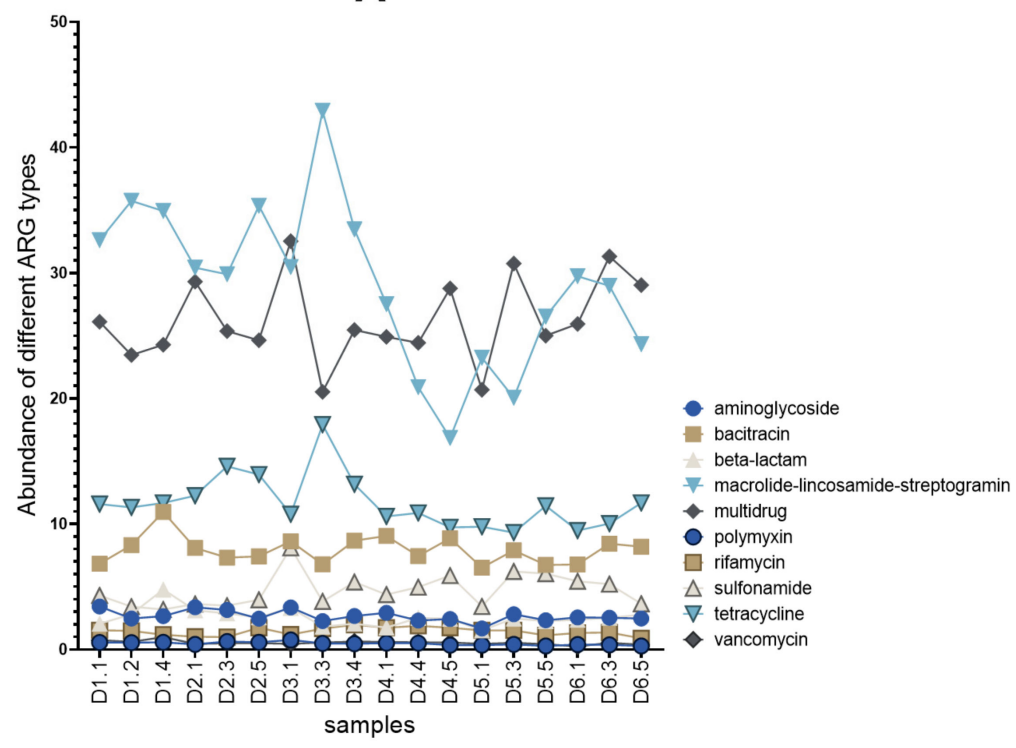

B

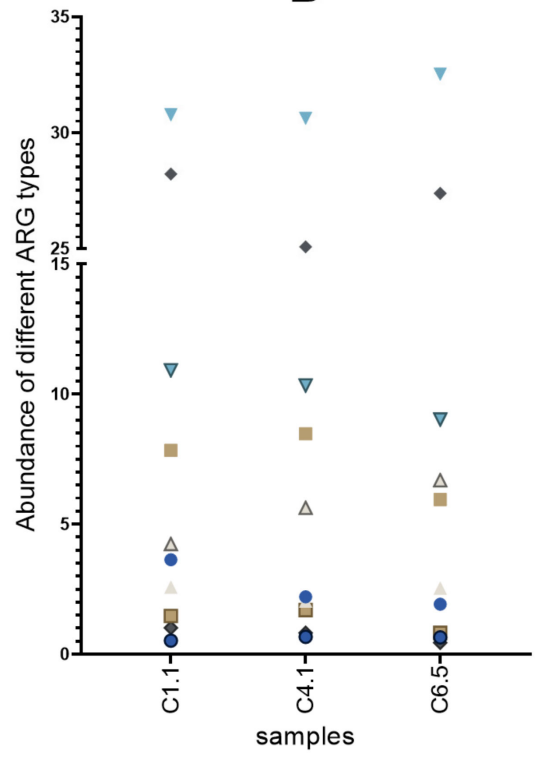

Figure 7. Abundance of ARGs [ppm] in process (A) and control bioreactors (B). The presented scale differs from that shown in Figure 3. D-dose ID, C-control samples.
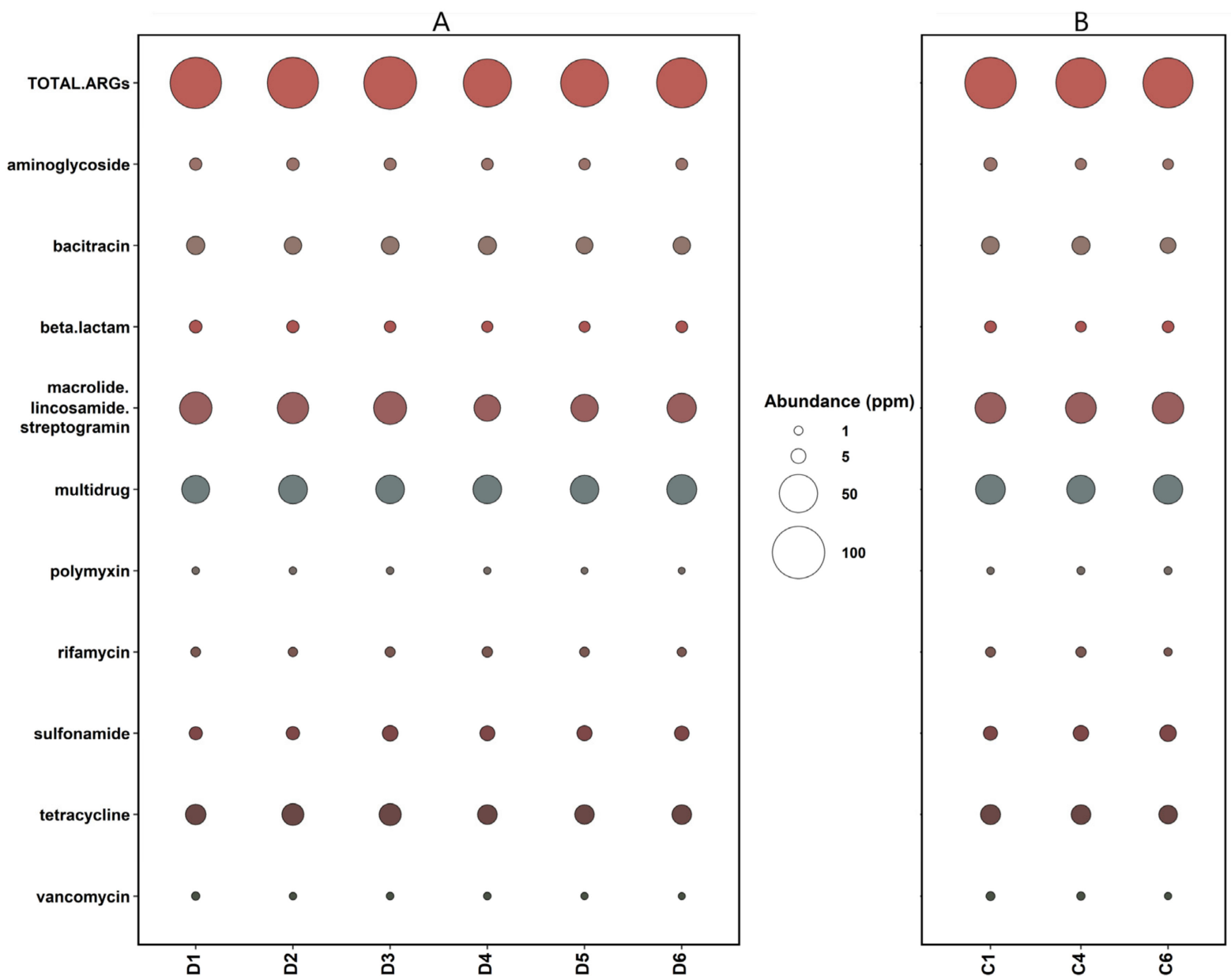

Figure 8. A bubble plot presenting changes in ARG abundance [ppm] in sewage sludge samples from process (A) and control bioreactors (B). The mean values noted in each experiment were used in the analysis. D-dose ID, C-control samples, ARGs-antibiotic resistance genes. 
A number of studies analyzed antibiotic concentrations in wastewater flowing into WWTPs as well as in sewage sludge which is utilized as a substrate for methane fermentation [40]. Metronidazole, amoxicillin and ciprofloxacin were detected in wastewater entering WWTPs at concentrations of 69-250, 120-280 and 184-1260 ng/L, respectively [40,90]. These values exceed the predicted no-effect concentrations (PNEC) $(125,250$ and $64 \mathrm{ng} / \mathrm{L}$, respectively) suggested by Bengtsson-Palme and Larsson [91]. The predicted no-effect concentration is a concentration of an antibiotic which, when exceeded, can promote the spread of antibiotic resistance in the environment. Bacteria present in the process bioreactor could have adapted to metronidazole, amoxicillin and ciprofloxacin within the concentration ranges analyzed in this study. These observations also point to the absence of synergistic reactions between the tested antimicrobial substances.

\subsection{Correlations between Anaerobic Digestion Parameters, Microbial Biodiversity and Selected ARGs}

The data relating to methane production and the abundance of different ARGs and microbial groups in the process bioreactor during long-term anaerobic digestion were processed statistically by principal component analysis (PCA) (Figure 9). The first two principal components (PC1 and PC2) explained 40.3\% and 19.7\% of the variance, respectively. Three distinct clusters were identified. The first cluster contained OTUs characteristic of Bacteroidetes, Proteobacteria, Candidatus Cloacimonetes and genes encoding resistance to sulfonamides and rifamycin. The phyla Bacteroidetes and Proteobacteria represented by hydrolytic and acidogenic bacteria, and Candidatus Cloacimonetes as a potential acetogenic microorganism were grouped together with methane production. This cluster also contained the results obtained in experimental series D3, D4 and D5, which were characterized by an increase in methane production and the highest average abundance of sulfonamide and rifamycin resistance genes (Figure 7A,B). The results obtained in the first experimental series (D1) formed a separate cluster containing the phyla Firmicutes, Actinobacteria and Chloroflexi, as well as genes encoding resistance to polymyxins, bacitracin and vancomycin. The abundance of the above phyla (Figure 4A) and ARGs (Table S8) was highest during exposure to the lowest concentrations of the tested antibiotics (D1), and it decreased in successive experimental series of long-term anaerobic digestion. Moreover, a correlation between the prevalence of the phyla Actinobacteria and Chloroflexi, and the abundance of ARGs encoding resistance to vancomycin was visualized in Circos (Figure S2). The last cluster contained the results obtained in the final experimental series (D6), the abundance of multidrug resistance genes, and the prevalence of the phyla Tenericutes and Nitrospirae and the kingdom Archaea which increased in response to the highest doses of the tested antibiotics. It indicates that the share of a particular phylum of microorganisms varied depending on the experimental series and the dose of the mixture of antibiotics. These changes resulted in various methane production and changes in the ARG pool. 


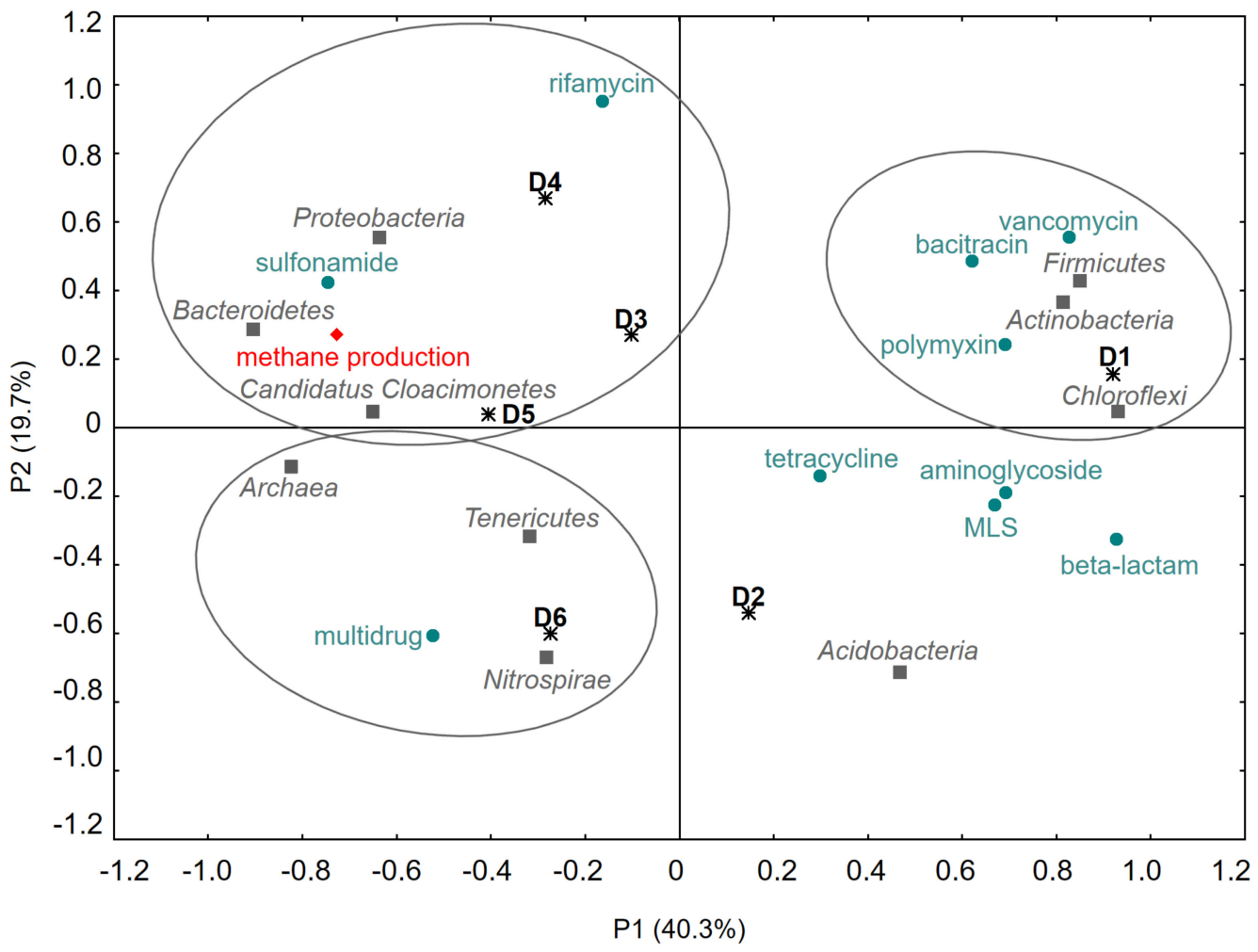

Figure 9. Ordination analysis of samples from the process bioreactors (D1-D6). Principal component analysis (PCA) of microbial abundance, ARG abundance and methane production. D-dose ID.

\section{Conclusions}

Long-term supplementation of sewage sludge with a combination of metronidazole, amoxicillin and ciprofloxacin applied at different doses did not induce significant changes in the concentrations of VFAs, or the total abundance of ARGs. However, the tested antimicrobials significantly decreased methane production and modified the structure of microbial populations. Moreover, exposure to antibiotics significantly increased the number of OTUs characteristic of Archaea in sewage sludge, but these changes did not affect the efficiency of biogas production. The observed changes in the composition of methanogenic consortia suggest that the hydrogen-dependent methylotrophic pathway of methanogenesis may significantly contribute to the stability of anaerobic digestion in the presence of antimicrobial substances.

The predominance of the phylum Acidobacteria in bioreactors also indicates that the effect of antimicrobials on the anaerobic digestion of sewage sludge is determined not only by the presence of antibiotics, but also by substrate and the substrate-specific composition of microbiota. Moreover, this study provides further evidence to support the importance of Candidatus Cloacimonetes in anaerobic digestion, which has been reported in the literature.

The greatest changes in microbial diversity were noted in supplemented sewage sludge exposed to the highest dose of the tested antibiotics, relative to control. These findings suggest that higher concentrations of antimicrobials in sewage sludge can substantially compromise the efficiency of anaerobic digestion. Antibiotic consumption is growing steadily worldwide, which increases antimicrobial concentrations in wastewater flowing into WWTPs and in sewage sludge. Exposure to antibiotics may compromise the efficiency of methane fermentation of this substrate.

Supplementary Materials: The following supporting information can be downloaded at: https:/ / www.mdpi.com/article/10.3390/en15051826/s1, Table S1: The mean values of pH, FOS/TAC ratio, TS, VS, TP and TN in each of the experimental series in the control (CB) and process (PB) bioreactors. TS—total solids, vs.—volatile solids, TP—total phosphorus, TN—total nitrogen; Table S2: Differences 
in methane production between samples from process and control bioreactors (two-way ANOVA; $p<0.05$ ); Table S3: Differences in VFA (volatile fatty acid) content between samples from process and control bioreactors (two-way ANOVA; $p<0.05$ ); Table S4: Sequencing analysis data presenting the abundance of dominant bacterial phyla in all sequenced samples, expressed in reads per million reads [ppm]; Table S5: Sequencing analysis data presenting the abundance of four orders of methanogens in all sequenced samples, expressed in reads per million reads [ppm]; Table S6: Correlations between the occurrence of Archaea in the process bioreactor (Spearman's rank correlation coefficient; significant results are marked in red, $p<0.05)$; Table S7: Correlations between the occurrence of bacterial phyla in the process bioreactor (Spearman's rank correlation coefficient; significant results are marked in red, $p<0.05)$; Table S8: Sequencing analysis data presenting the abundance of ARG classes in all sequenced samples, expressed in reads per million reads [ppm]; Figure S1: Content of VFAs (g/L) in bioreactors containing antimicrobials and in the control bioreactor. $\mathrm{C}$-control samples, D-dose ID, VFAs-volatile fatty acids. For example, "C/D 1.1" indicates samples C1.1 and D1.1 (green and blue points on the line graph, respectively); Figure S2: The taxonomic distribution of microbial diversity and ARG abundance in all sequenced samples of sewage sludge. The links describe the Pearson correlation $(>0.7, p<0.05)$ between the abundance of ARGs and the relative abundance of the bacterial community on different taxonomic levels.

Author Contributions: Conceptualization, M.C., M.H., E.K. and S.B.; methodology, M.C., M.H. and P.R.; software, Ł.P. and J.P.J.; validation, M.C. and M.H.; investigation, M.C.; resources, M.H.; data curation, Ł.P. and J.P.J.; writing-original draft preparation, M.C. and I.W.; writing-review and editing, M.C. and M.H.; visualization, M.C. and Ł.P.; supervision, M.H.; project administration, M.H.; funding acquisition, M.H. All authors have read and agreed to the published version of the manuscript.

Funding: This research was funded by National Science Center (Poland), grant number No. 2016/23/ B/NZ9/03669, and by the Minister of Science and Higher Education under the "Regional Initiative of Excellence" program for the years 2019-2022 (Project No. 010/RID/2018/19, funding 12.000.000 PLN).

Informed Consent Statement: Not applicable.

Data Availability Statement: A total of 21 metagenomic samples were placed under accession No. PRJEB48473 in the European Nucleotide Archive (ENA) database. This data can be found here: https: / / www.ebi.ac.uk/ena/browser/view / PRJEB48473 (accessed on 7 January 2022).

Conflicts of Interest: The authors declare no conflict of interest.

\section{References}

1. Carvalho, I.T.; Santos, L. Antibiotics in the aquatic environments: A review of the European scenario. Environ. Int. 2016, 94, 736-757. [CrossRef] [PubMed]

2. Al-Riyami, I.M.; Ahmed, M.; Al-Busaidi, A.; Choudri, B.S. Antibiotics in wastewaters: A review with focus on Oman. Appl. Water Sci. 2018, 8, 199. [CrossRef]

3. Bound, J.P.; Voulvoulis, N. Household Disposal of Pharmaceuticals as a Pathway for Aquatic Contamination in the United Kingdom. Environ. Health Perspect. 2005, 113, 1705-1711. [CrossRef] [PubMed]

4. Mitchell, S.M.; Ullman, J.L.; Teel, A.; Watts, R.J.; Frear, C. The effects of the antibiotics ampicillin, florfenicol, sulfamethazine, and tylosin on biogas production and their degradation efficiency during anaerobic digestion. Bioresour. Technol. 2013, 149, $244-252$. [CrossRef]

5. Czatzkowska, M.; Harnisz, M.; Korzeniewska, E.; Rusanowska, P.; Bajkacz, S.; Felis, E.; Jastrzębski, J.P.; Paukszto, Ł.; Koniuszewska, I. The impact of antimicrobials on the efficiency of methane fermentation of sewage sludge, changes in microbial biodiversity and the spread of antibiotic resistance. J. Hazard. Mater. 2021, 416, 125773. [CrossRef]

6. Grobelak, A.; Grosser, A.; Kacprzak, M.; Kamizela, T. Sewage sludge processing and management in small and medium-sized municipal wastewater treatment plant-new technical solution. J. Environ. Manag. 2019, 234, 90-96. [CrossRef]

7. Ju, F.; Li, B.; Ma, L.; Wang, Y.; Huang, D.; Zhang, T. Antibiotic resistance genes and human bacterial pathogens: Co-occurrence, removal, and enrichment in municipal sewage sludge digesters. Water Res. 2016, 91, 1-10. [CrossRef]

8. Shin, J.; Rhee, C.; Shin, J.; Jang, H.M.; Shin, S.G.; Kim, Y.M. Determining the composition of bacterial community and relative abundance of specific antibiotics resistance genes via thermophilic anaerobic digestion of sewage sludge. Bioresour. Technol. 2020, 311, 123510. [CrossRef] 
9. Yu, H.; Zhao, Q.; Meng, F.; Ruan, L.; Sun, T.; Liu, X.; Liu, W.; Zhu, Y.; Li, W.; Meng, F. Deciphering the role of calcium peroxide on the fate of antibiotic resistance genes and mobile genetic elements during bioelectrochemically-assisted anaerobic composting of excess dewatered sludge. Chem. Eng. J. 2020, 397, 125355. [CrossRef]

10. Xiao, Y.; Raheem, A.; Ding, L.; Chen, W.-H.; Chen, X.; Wang, F.; Lin, S.-L. Pretreatment, modification and applications of sewage sludge-derived biochar for resource recovery-A review. Chemosphere 2021, 287, 131969. [CrossRef]

11. Chen, Q.; An, X.; Li, H.; Su, J.; Ma, Y.; Zhu, Y.-G. Long-term field application of sewage sludge increases the abundance of antibiotic resistance genes in soil. Environ. Int. 2016, 9, 1-10. [CrossRef] [PubMed]

12. Qiao, M.; Ying, G.-G.; Singer, A.; Zhu, Y.-G. Review of antibiotic resistance in China and its environment. Environ. Int. 2018, 110, 160-172. [CrossRef] [PubMed]

13. Alonso, L.L.; Demetrio, P.M.; Capparelli, A.L.; Marino, D.J. Behavior of ionophore antibiotics in aquatic environments in Argentina: The distribution on different scales in water courses and the role of wetlands in depuration. Environ. Int. 2019, 133, 105144. [CrossRef]

14. Świątczak, P.; Cydzik-Kwiatkowska, A.; Rusanowska, P. Microbiota of anaerobic digesters in a full-scale wastewater treatment plant. Arch. Environ. Prot. 2017, 43, 53-60. [CrossRef]

15. Czatzkowska, M.; Harnisz, M.; Korzeniewska, E.; Koniuszewska, I. Inhibitors of the methane fermentation process with particular emphasis on the microbiological aspect: A review. Energy Sci. Eng. 2020, 8, 1880-1897. [CrossRef]

16. Chen, Y.; Cheng, J.J.; Creamer, K.S. Inhibition of anaerobic digestion process: A review. Bioresour. Technol. 2008, 99, 4044-4064. [CrossRef] [PubMed]

17. Scarlat, N.; Dallemand, J.-F.; Fahl, F. Biogas: Developments and perspectives in Europe. Renew. Energy 2018, 129, 457-472. [CrossRef]

18. Kohanski, M.A.; Dwyer, D.J.; Collins, J.J. How antibiotics kill bacteria: From targets to networks. Nat. Rev. Microbiol. 2010, 8, 423-435. [CrossRef]

19. Schmidt, V.M.; Pinchbeck, G.; McIntyre, K.M.; Nuttall, T.; McEwan, N.; Dawson, S.; Williams, N.J. Routine antibiotic therapy in dogs increases the detection of antimicrobial-resistant faecal Escherichia coli. J. Antimicrob. Chemother. 2018, 73, 3305-3316. [CrossRef]

20. Rusanowska, P.; Zieliński, M.; Dębowski, M.; Harnisz, M.; Korzeniewska, E.; Amenda, E. Inhibition of Methane Fermentation by Antibiotics Introduced to Municipal Anaerobic Sludge. Proceedings 2018, 2, 1274. [CrossRef]

21. Amani, T.; Nosrati, M.; Sreekrishnan, T.R. Anaerobic digestion from the viewpoint of microbiological, chemical, and operational aspects-A review. Environ. Rev. 2010, 18, 255-278. [CrossRef]

22. Alvarado, A.; Montañez-Hernández, L.E.; Palacio-Molina, S.L.; Oropeza-Navarro, R.; Luévanos-Escareño, M.P.; Balagurusamy, N. Microbial trophic interactions and mcrA gene expression in monitoring of anaerobic digesters. Front. Microbiol. $2014,5,597$. [CrossRef] [PubMed]

23. Becerra-Castro, C.; Lopes, A.R.; Vaz-Moreira, I.; Silva, E.F.; Manaia, C.M.; Nunes, O.C. Wastewater reuse in irrigation: A microbiological perspective on implications in soil fertility and human and environmental health. Environ. Int. 2015, 75, 117-135. [CrossRef]

24. Xu, Y.-B.; Hou, M.-Y.; Li, Y.-F.; Huang, L.; Ruan, J.-J.; Zheng, L.; Qiao, Q.-X.; Du, Q.-P. Distribution of tetracycline resistance genes and AmpC $\beta$-lactamase genes in representative non-urban sewage plants and correlations with treatment processes and heavy metals. Chemosphere 2017, 170, 274-281. [CrossRef]

25. Barancheshme, F.; Munir, M. Development of Antibiotic Resistance in Wastewater Treatment Plants. In Antimicrobial Resistance—A Global Threat; IntechOpen: London, UK, 2019; pp. 75-92. [CrossRef]

26. Sun, C.; Li, W.; Chen, Z.; Qin, W.; Wen, X. Responses of antibiotics, antibiotic resistance genes, and mobile genetic elements in sewage sludge to thermal hydrolysis pre-treatment and various anaerobic digestion conditions. Environ. Int. 2019, 133, 105156. [CrossRef] [PubMed]

27. Tian, Z.; Zhang, Y.; Yang, M. Chronic impacts of oxytetracycline on mesophilic anaerobic digestion of excess sludge: Inhibition of hydrolytic acidification and enrichment of antibiotic resistome. Environ. Pollut. 2018, 238, 1017-1026. [CrossRef]

28. Zhang, X.; Gu, J.; Wang, X.; Zhang, K.; Yin, Y.; Zhang, R.; Zhang, S. Effects of tylosin, ciprofloxacin, and sulfadimidine on mcrA gene abundance and the methanogen community during anaerobic digestion of cattle manure. Chemosphere 2019, 221, 81-88. [CrossRef]

29. Wang, M.; Li, R.; Zhao, Q. Distribution and removal of antibiotic resistance genes during anaerobic sludge digestion with alkaline, thermal hydrolysis and ultrasonic pretreatments. Front. Environ. Sci. Eng. 2019, 13, 43. [CrossRef]

30. Redhead, S.; Nieuwland, J.; Esteves, S.; Lee, D.-H.; Kim, D.-W.; Mathias, J.; Cha, C.-J.; Toleman, M.; Dinsdale, R.; Guwy, A.; et al Fate of antibiotic resistant E. coli and antibiotic resistance genes during full scale conventional and advanced anaerobic digestion of sewage sludge. PLoS ONE 2020, 15, e0237283. [CrossRef]

31. Koniuszewska, I.; Czatzkowska, M.; Harnisz, M.; Korzeniewska, E. The Impact of Antimicrobial Substances on the Methanogenic Community during Methane Fermentation of Sewage Sludge and Cattle Slurry. Appl. Sci. 2021, 11, 369. [CrossRef]

32. Hernández Ceruelos, A.; Romero-Quezada, L.C.; Ruvalcaba Ledezma, J.C.; López Contreras, L. Therapeutic uses of metronidazole and its side effects: An update. Eur. Rev. Med. Pharmacol. Sci. 2019, 23, 397-401. [PubMed]

33. Davis, J.L.; Papich, M.G. Chapter 65-Antimicrobial Therapy. In Equine Infectious Diseases, 2nd ed.; Sellon, D.C., Long, M.T., Eds.; Saunders WB: St. Louis, MO, USA, 2014; pp. 571-584.e5. [CrossRef] 
34. Kong, K.-F.; Schneper, L.; Mathee, K. Beta-lactam antibiotics: From antibiosis to resistance and bacteriology. APMIS 2010, 118, 1-36. [CrossRef] [PubMed]

35. Pandey, N.; Cascella, M. Beta Lactam Antibiotics. In StatPearls; StatPearls Publishing: Treasure Island, FL, USA, 2021.

36. Thai, T.; Salisbury, B.H.; Zito, P.M. Ciprofloxacin. In StatPearls; StatPearls Publishing: Treasure Island, FL, USA, 2021.

37. D’addazio, L.B.; Moraes, S.R. Microrganismos isolados de infecção do trato urinário da comunidade. Rev. Saúde Pública 2015, 6, 11-13. [CrossRef]

38. Reis, A.C.C.; Santos, S.R.D.S.; de Souza, S.C.; Saldanha, M.G.; Pitanga, T.N.; Oliveira, R.R. Ciprofloxacin resistance pattern among bacteria isolated from patients with community-acquired urinary tract infection. Rev. Inst. Med. Trop. São Paulo 2016, 58, 53. [CrossRef] [PubMed]

39. Mustapha, N.A.; Sakai, K.; Shirai, Y.; Maeda, T. Impact of different antibiotics on methane production using waste-activated sludge: Mechanisms and microbial community dynamics. Appl. Microbiol. Biotechnol. 2016, 100, 9355-9364. [CrossRef]

40. Giebułtowicz, J.; Nałęcz-Jawecki, G.; Harnisz, M.; Kucharski, D.; Korzeniewska, E.; Płaza, G. Environmental Risk and Risk of Resistance Selection Due to Antimicrobials' Occurrence in Two Polish Wastewater Treatment Plants and Receiving Surface Water. Molecules 2020, 25, 1470. [CrossRef]

41. Kisielewska, M.; Debowski, M.; Zieliński, M. Improvement of biohydrogen production using a reduced pressure fermentation. Bioprocess Biosyst. Eng. 2015, 38, 1925-1933. [CrossRef]

42. APHA. Standard Methods for Water and Wastewater Examination, 19th ed.; American Public Health Association: Washington, DC, USA, 1995.

43. Kneaddata v. 0.7.6 Software. Available online: https://github.com/biobakery/kneaddata (accessed on 12 November 2021).

44. Franzosa, E.A.; McIver, L.J.; Rahnavard, G.; Thompson, L.R.; Schirmer, M.; Weingart, G.; Lipson, K.S.; Knight, R.; Caporaso, J.G.; Segata, N.; et al. Species-level functional profiling of metagenomes and metatranscriptomes. Nat. Methods 2018, 15, 962-968. [CrossRef]

45. Segata, N.; Waldron, L.; Ballarini, A.; Narasimhan, V.; Jousson, O.; Huttenhower, C. Metagenomic microbial community profiling using unique clade-specific marker genes. Nat. Methods 2012, 9, 811-814. [CrossRef]

46. McMurdie, P.J.; Holmes, S. Phyloseq: An R package for reproducible interactive analysis and graphics of microbiome census data. PLoS ONE 2013, 8, e61217. [CrossRef]

47. Gu, Z.; Gu, L.; Eils, R.; Schlesner, M.; Brors, B. circlize implements and enhances circular visualization in R. Bioinformatics 2014, 30, 2811-2812. [CrossRef] [PubMed]

48. Asnicar, F.; Weingart, G.; Tickle, T.; Huttenhower, C.; Segata, N. Compact graphical representation of phylogenetic data and metadata with GraPhlAn. PeerJ 2015, 3, e1029. [CrossRef] [PubMed]

49. Yin, X.; Jiang, X.-T.; Chai, B.; Li, L.; Yang, Y.; Cole, J.R.; Tiedje, J.M.; Zhang, T. ARGs-OAP v2.0 with an expanded SARG database and Hidden Markov Models for enhancement characterization and quantification of antibiotic resistance genes in environmental metagenomes. Bioinformatics 2018, 34, 2263-2270. [CrossRef]

50. Hclust2 Python Script. Available online: https://github.com/SegataLab/hclust2 (accessed on 15 November 2021).

51. The Custom R Function. Available online: https://raw.githubusercontent.com/BioinfoCoreFacility/metaGen/main/R/cor. OTUvsGENES.R (accessed on 15 November 2021).

52. Álvarez, J.; Otero, L.; Lema, J.; Omil, F. The effect and fate of antibiotics during the anaerobic digestion of pig manure. Bioresour. Technol. 2010, 101, 8581-8586. [CrossRef] [PubMed]

53. Lagator, M.; Uecker, H.; Neve, P. Adaptation at different points along antibiotic concentration gradients. Biol. Lett. 2021, 17, 20200913. [CrossRef]

54. Xiong, L.; Yang, Y.; Ye, Y.-N.; Teng, J.L.L.; Chan, E.; Watt, R.M.; Guo, F.-B.; Lau, S.K.P.; Woo, P.C.Y. Laribacter hongkongensisanaerobic adaptation mediated by arginine metabolism is controlled by the cooperation of FNR and ArgR. Environ. Microbiol. 2017, 19, 1266-1280. [CrossRef]

55. Lallai, A.; Mura, G.; Onnis, N. The effects of certain antibiotics on biogas production in the anaerobic digestion of pig waste slurry Bioresour. Technol. 2002, 82, 205-208. [CrossRef]

56. Spielmeyer, A.; Breier, B.; Groißmeier, K.; Hamscher, G. Elimination patterns of worldwide used sulfonamides and tetracyclines during anaerobic fermentation. Bioresour. Technol. 2015, 193, 307-314. [CrossRef]

57. Harb, M.; Wei, C.-H.; Wang, N.; Amy, G.; Hong, P.-Y. Organic micropollutants in aerobic and anaerobic membrane bioreactors: Changes in microbial communities and gene expression. Bioresour. Technol. 2016, 218, 882-891. [CrossRef]

58. Lu, X.; Zhen, G.; Liu, Y.; Hojo, T.; Estrada, A.L.; Li, Y.-Y. Long-term effect of the antibiotic cefalexin on methane production during waste activated sludge anaerobic digestion. Bioresour. Technol. 2014, 169, 644-651. [CrossRef]

59. Shah, F.A.; Mahmood, Q.; Maroof Shah, M.; Pervez, A.; Ahmad Asad, S. Retracted: Microbial Ecology of Anaerobic Digesters: The Key Players of Anaerobiosis. Sci. World J. 2017, 2017, 3852369. [CrossRef]

60. De Chaves, M.G.; Silva, G.G.Z.; Rossetto, R.; Edwards, R.A.; Tsai, S.M.; Navarrete, A.A. Acidobacteria Subgroups and Their Metabolic Potential for Carbon Degradation in Sugarcane Soil Amended with Vinasse and Nitrogen Fertilizers. Front. Microbiol. 2019, 10, 1680. [CrossRef] [PubMed]

61. Kristensen, J.M.; Singleton, C.; Clegg, L.-A.; Petriglieri, F.; Nielsen, P.H. High Diversity and Functional Potential of Undescribed "Acidobacteriota" in Danish Wastewater Treatment Plants. Front. Microbiol. 2021, 12, 643950. [CrossRef] [PubMed] 
62. Sundberg, C.; Al-Soud, W.A.; Larsson, M.; Alm, E.; Yekta, S.S.; Svensson, B.H.; Sørensen, S.J.; Karlsson, A. 454 pyrosequencing analyses of bacterial and archaeal richness in 21 full-scale biogas digesters. FEMS Microbiol. Ecol. 2013, 85, 612-626. [CrossRef] [PubMed]

63. Yang, Y.; Yu, K.; Xia, Y.; Lau, F.T.K.; Tang, D.T.W.; Fung, W.C.; Fang, H.H.P.; Zhang, T. Metagenomic analysis of sludge from full-scale anaerobic digesters operated in municipal wastewater treatment plants. Appl. Microbiol. Biotechnol. 2014, 98, 5709-5718 [CrossRef]

64. Walter, A.; Probst, M.; Franke-Whittle, I.H.; Ebner, C.; Podmirseg, S.M.; Etemadi-Shalamzari, M.; Hupfauf, S.; Insam, H. Microbiota in anaerobic digestion of sewage sludge with and without co-substrates. Water Environ. J. 2018, 33, 214-222. [CrossRef]

65. Talavera-Caro, A.G.; Lira, I.O.H.-D.; Cruz, E.R.; Sánchez-Muñoz, M.A.; Balagurusamy, N. The Realm of Microorganisms in Biogas Production: Microbial Diversity, Functional Role, Community Interactions, and Monitoring the Status of Biogas Plant. In Biogas Production; Balagurusamy, N., Chandel, A.K., Eds.; Springer: Cham, Switzerland, 2020. [CrossRef]

66. Lim, S.D.; Mayer, J.A.; Yim, W.C.; Cushman, J.C. Plant tissue succulence engineering improves water-use efficiency, water-deficit stress attenuation and salinity tolerance in Arabidopsis. Plant J. 2020, 103, 1049-1072. [CrossRef]

67. Müller, B.; Sun, L.; Westerholm, M.; Schnürer, A. Bacterial community composition and fhs profiles of low-and high-ammonia biogas digesters reveal novel syntrophic acetate-oxidising bacteria. Biotechnol. Biofuels 2016, 9, 48. [CrossRef]

68. Klang, J.; Szewzyk, U.; Bock, D.; Theuerl, S. Nexus between the microbial diversity level and the stress tolerance within the biogas process. Anaerobe 2019, 56, 8-16. [CrossRef]

69. Braz, G.H.; Fernandez-Gonzalez, N.; Lema, J.M.; Carballa, M. Organic overloading affects the microbial interactions during anaerobic digestion in sewage sludge reactors. Chemosphere 2019, 222, 323-332. [CrossRef]

70. Poirier, S.; Déjean, S.; Midoux, C.; Cao, K.-A.L.; Chapleur, O. Integrating independent microbial studies to build predictive models of anaerobic digestion inhibition by ammonia and phenol. Bioresour. Technol. 2020, 316, 123952. [CrossRef]

71. Singh, A.; Müller, B.; Schnürer, A. Profiling temporal dynamics of acetogenic communities in anaerobic digesters using nextgeneration sequencing and T-RFLP. Sci. Rep. 2021, 11, 13298. [CrossRef]

72. Veloo, A.; Baas, W.; Haan, F.; Coco, J.; Rossen, J. Prevalence of antimicrobial resistance genes in Bacteroides spp. and Prevotella spp. Dutch clinical isolates. Clin. Microbiol. Infect. 2019, 25, 1156.e9-1156.e13. [CrossRef] [PubMed]

73. Duranti, S.; Mangifesta, M.; Lugli, G.A.; Turroni, F.; Anzalone, R.; Milani, C.; Mancabelli, L.; Ossiprandi, M.C.; Ventura, M. Bifidobacterium vansinderenii sp. nov., isolated from faeces of emperor tamarin (Saguinus imperator). Int. J. Syst. Evol. Microbiol. 2017, 67, 3987-3995. [CrossRef]

74. Rozman, V.; Lorbeg, P.M.; Accetto, T.; Matijašić, B.B. Characterization of antimicrobial resistance in lactobacilli and bifidobacteria used as probiotics or starter cultures based on integration of phenotypic and in silico data. Int. J. Food Microbiol. 2019, 314, 108388. [CrossRef] [PubMed]

75. Burkovski, A. Cell Envelope of Corynebacteria: Structure and Influence on Pathogenicity. ISRN Microbiol. 2013, $2013,935736$. [CrossRef]

76. Bernard, K.A.; Pacheco, A.L.; Loomer, C.; Burdz, T.; Wiebe, D.; Huynh, C.; Kaplen, B.; Olson, A.B.; Cnockaert, M.; Eguchi, H.; et al. Corynebacterium lowii sp. nov. and Corynebacterium oculi sp. nov., derived from human clinical disease and an emended description of Corynebacterium mastitidis. Int. J. Syst. Evol. Microbiol. 2016, 66, 2803-2812. [CrossRef]

77. Liu, Y.; Whitman, W.B. Metabolic, Phylogenetic, and Ecological Diversity of the Methanogenic Archaea. Ann. N. Y. Acad. Sci. 2008, 1125, 171-189. [CrossRef] [PubMed]

78. Dridi, B.; Fardeau, M.-L.; Ollivier, B.; Raoult, D.; Drancourt, M. Methanomassiliicoccus luminyensis gen. nov., sp. nov., a methanogenic archaeon isolated from human faeces. Int. J. Syst. Evol. Microbiol. 2012, 62, 1902-1907. [CrossRef] [PubMed]

79. Lackner, N.; Hintersonnleitner, A.; Wagner, A.O.; Illmer, P. Hydrogenotrophic Methanogenesis and Autotrophic Growth of Methanosarcina thermophila. Archaea 2018, 2018, 4712608. [CrossRef] [PubMed]

80. Guo, J.; Peng, Y.; Ni, B.-J.; Han, X.; Fan, L.; Yuan, Z. Dissecting microbial community structure and methane-producing pathways of a full-scale anaerobic reactor digesting activated sludge from wastewater treatment by metagenomic sequencing. Microb. Cell Factories 2015, 14, 1-11. [CrossRef] [PubMed]

81. Liu, C.; Li, H.; Zhang, Y.; Si, D.; Chen, Q. Evolution of microbial community along with increasing solid concentration during high-solids anaerobic digestion of sewage sludge. Bioresour. Technol. 2016, 216, 87-94. [CrossRef] [PubMed]

82. Enzmann, F.; Mayer, F.; Rother, M.; Holtmann, D. Methanogens: Biochemical background and biotechnological applications. AMB Express 2018, 8, 1-22. [CrossRef] [PubMed]

83. Miura, Y.; Hiraiwa, M.N.; Ito, T.; Itonaga, T.; Watanabe, Y.; Okabe, S. Bacterial community structures in MBRs treating municipal wastewater: Relationship between community stability and reactor performance. Water Res. 2007, 41, 627-637. [CrossRef]

84. Song, M.; Shin, S.G.; Hwang, S. Methanogenic population dynamics assessed by real-time quantitative PCR in sludge granule in upflow anaerobic sludge blanket treating swine wastewater. Bioresour. Technol. 2010, 101, S23-S28. [CrossRef] [PubMed]

85. Zhang, C.-J.; Pan, J.; Liu, Y.; Duan, C.-H.; Li, M. Genomic and transcriptomic insights into methanogenesis potential of novel methanogens from mangrove sediments. Microbiome 2020, 8, 1-12. [CrossRef] [PubMed]

86. Xu, R.; Yang, Z.-H.; Zheng, Y.; Wang, Q.-P.; Bai, Y.; Liu, J.-B.; Zhang, Y.-R.; Xiong, W.-P.; Lu, Y.; Fan, C.-Z. Metagenomic analysis reveals the effects of long-term antibiotic pressure on sludge anaerobic digestion and antimicrobial resistance risk. Bioresour. Technol. 2019, 282, 179-188. [CrossRef] 
87. Ni, B.-J.; Zeng, S.; Wei, W.; Dai, X.; Sun, J. Impact of roxithromycin on waste activated sludge anaerobic digestion: Methane production, carbon transformation and antibiotic resistance genes. Sci. Total Environ. 2019, 703, 134899. [CrossRef]

88. Zou, Y.; Qian, X.; Liu, X.; Song, Y.; Song, C.; Wu, S.; An, Y.; Yuan, R.; Wang, Y.; Xie, Y. The effect of antibiotic resistance onHelicobacter pylorieradication efficacy: A systematic review and meta-analysis. Helicobacter 2020, 25, e12714. [CrossRef]

89. Shi, Y.; Zhang, H.; Tian, Z.; Yang, M.; Zhang, Y. Characteristics of ARG-carrying plasmidome in the cultivable microbial community from wastewater treatment system under high oxytetracycline concentration. Appl. Microbiol. Biotechnol. 2018, 102, 1847-1858. [CrossRef]

90. Lamm, A.; Gozlan, I.; Rotstein, A.; Avisar, D. Detection of amoxicillin-diketopiperazine-2' ${ }^{\prime} 5^{\prime}$ in wastewater samples. J. Environ. Sci. Health Part A 2009, 44, 1512-1517. [CrossRef] [PubMed]

91. Bengtsson-Palme, J.; Larsson, D.J. Concentrations of antibiotics predicted to select for resistant bacteria: Proposed limits for environmental regulation. Environ. Int. 2016, 86, 140-149. [CrossRef] [PubMed] 